San Jose State University

SJSU ScholarWorks

Master's Theses

Master's Theses and Graduate Research

Fall 2015

\title{
A Study of Laser Ablation Propulsion Using Polyoxymethelyne and a High Power Diode Laser
}

Michael David Kolesar

San Jose State University

Follow this and additional works at: https://scholarworks.sjsu.edu/etd_theses

\section{Recommended Citation}

Kolesar, Michael David, "A Study of Laser Ablation Propulsion Using Polyoxymethelyne and a High Power Diode Laser" (2015). Master's Theses. 4644.

DOI: https://doi.org/10.31979/etd.7mea-n99e

https://scholarworks.sjsu.edu/etd_theses/4644

This Thesis is brought to you for free and open access by the Master's Theses and Graduate Research at SJSU ScholarWorks. It has been accepted for inclusion in Master's Theses by an authorized administrator of SJSU ScholarWorks. For more information, please contact scholarworks@sjsu.edu. 


\title{
A STUDY OF LASER ABLATION PROPULSION USING POLYOXYMETHELYNE AND A HIGH POWER DIODE LASER
}

\author{
A Thesis \\ Presented to \\ The Faculty of the Charles W. Davidson School of Engineering \\ Aerospace Engineering Department \\ San Jose State University \\ In Partial Fulfillment \\ of the Requirements for the Degree \\ Master of Sciences
}

by

Michael D. Kolesar

December 2015 
(C) 2015

Michael D. Kolesar

ALL RIGHTS RESERVED 
The Designated Thesis Committee Approve the Thesis Titled

\section{A STUDY OF LASER ABLATION PROPULSION USING POLYOXYMETHELYNE AND A HIGH POWER DIODE LASER}

by

Michael D. Kolesar

APPROVED FOR THE DEPARTMENT OF AEROSPACE ENGINEERING SAN JOSE STATE UNIVERSITY

DECEMBER 2015

Dr. Nikos Mourtos

Dr. Periklis Papadopoulos

Mr. Marcus Murbach
Department of Aerospace Engineering

Department of Aerospace Engineering

Department of Aerospace Engineering 


\begin{abstract}
With an increased interest by universities, government and commercial groups in using constellations of pico and and nano satellites, the need for micro-thrusters to aid in the station-keeping capabilities has become strong. This report examines using polymers and a laser to ablate material as a potential propulsion option for station-keeping. Homopolymer polyoxymethelyne (POM), commonly known as Delrin ${ }^{\mathrm{TM}}$, was tested as a fuel for a high powered (20 Watt $980 \mathrm{~nm}$ ) solid state diode laser ablation thruster to be used for station-keeping on pico and nano sized satellites. The experiments required a partial vacuum to reduce the effects of air decomposition and remove water vapor during the ablation event. The vacuum chamber, shadowgraph, and an impulse measurement system were all designed and built around the 20-Watt laser. Three different sample thicknesses were tested (.005", .010", and .020") to determine the behavior of the polymer. The laser was focused onto the POM sample, which was mounted to a load cell and calibrated to measure the impulse of the system imparted by the laser pulse. The calculated thrust values ranged from $600 \mu \mathrm{N}$ to $1300 \mu \mathrm{N}$ with a high uncertainty due to the small sample size. The exhaust plume from the ablation event was captured using a shadowgraph. A low velocity was recorded because the chamber was not a complete vacuum, causing the exhaust plume to collide with the air molecules in the test chamber. However the load cell results suggested that $1.30 \mathrm{mN}$ per burst can be produced with an uncertainty of $30 \%$. With the work outlined in this paper, POM shows the promise and challenge of being a good candidate as a fuel material. POM warrants further development and investment as a fuel to be used with a laser ablation micro-thruster.
\end{abstract}




\section{Table of Contents}

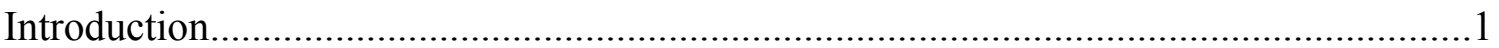

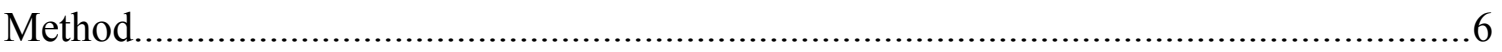

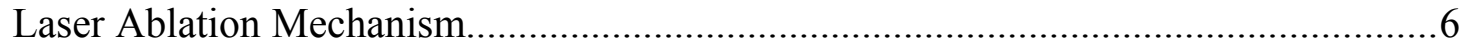

Fuel Material.................................................................................................. 7

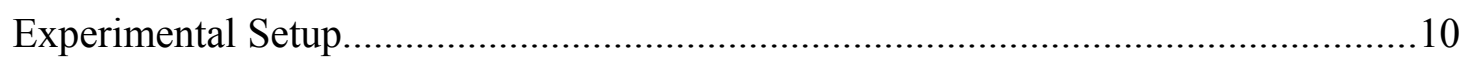

Initial setup of the experiment test area........................................................ 10

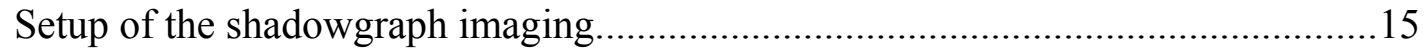

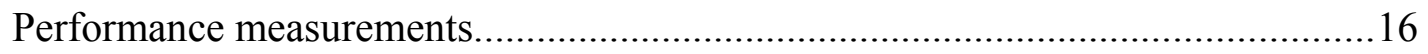

Experiment Constants and Variables............................................................ 18

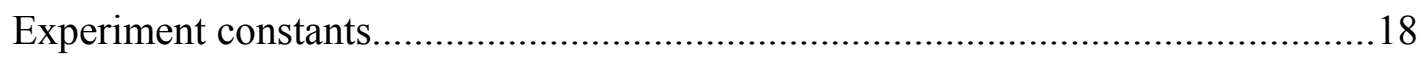

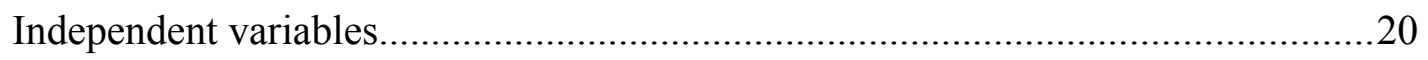

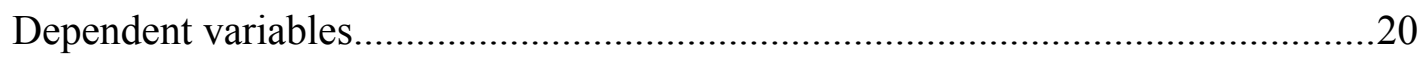

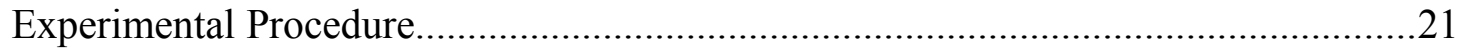

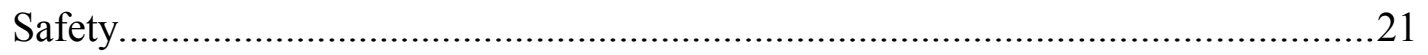

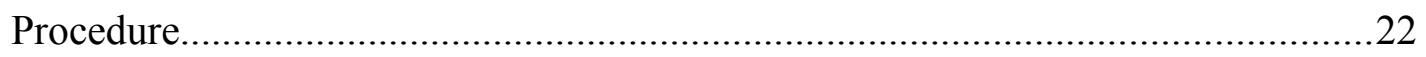

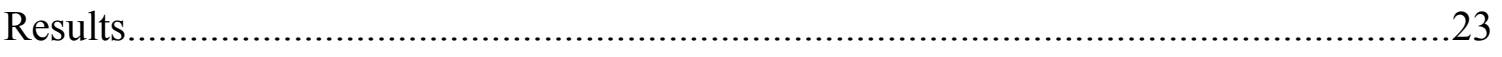

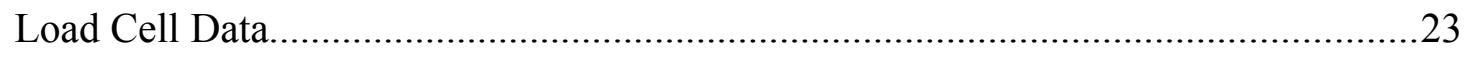

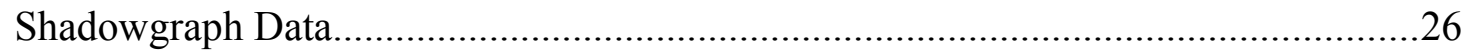

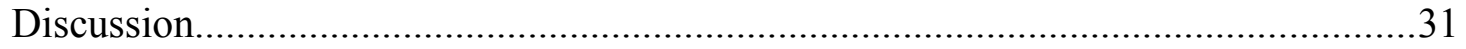

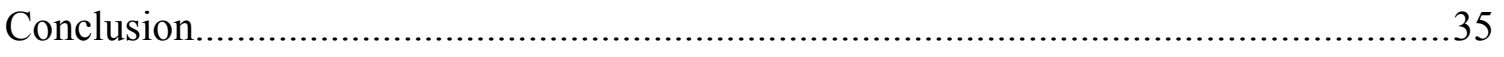

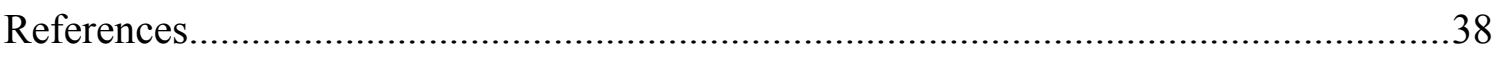

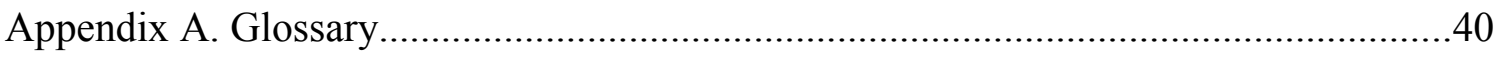

Appendix B. Processed Results From Raw Data for the .005" Thick Samples...............41 
Appendix C. Processed Results From Raw Data for the .010" Thick Samples...............42

Appendix D. Processed Results From Raw Data for the .020" Thick Samples..............43

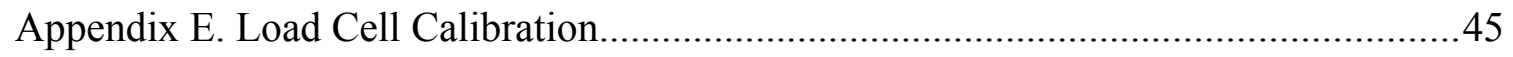

0.1 Gram Pendulum Dropped From 4565 and 90 Degrees....................................45

0.2 Gram Pendulum Dropped From 4565 and 90 Degrees.......................................45 


\section{List of Figures}

Figure 1: Micro-Thruster Schematic

Figure 2. Forward Plasma Acceleration - a.) Electron Emission, b.) Coulomb Explosion, and c.) Phase Explosion.

Figure 3. Chemical Structure of POM a.) Homopolymer and b.) Copolymer....................7

Figure 4. Reactants Produced by POM between 270 -670 K..................................... 9

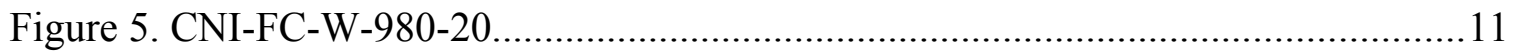

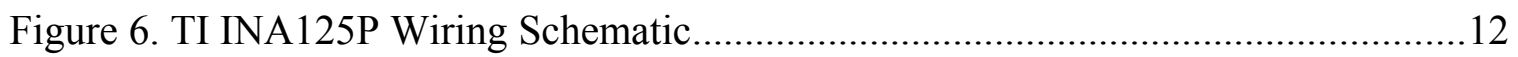

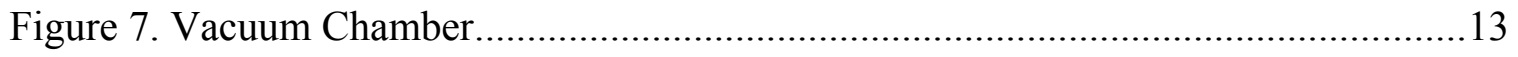

Figure 8. Diagram of Load Cell Setup......................................................................13

Figure 9. Experiment Layout.................................................................................. 14

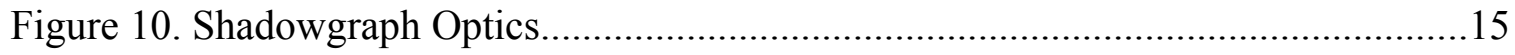

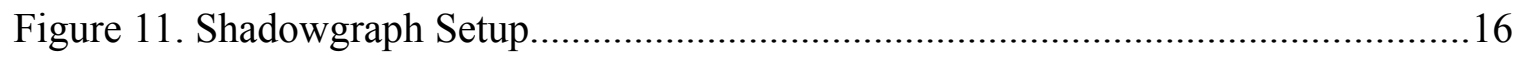

Figure 12. Pulsed vs. Modulated Laser.......................................................................19

Figure 13. Experiment Process.............................................................................22

Figure 14. Sample Experiment Log (Data Shown in Appendix) ..................................23

Figure 15: Sensor Impulse Values vs. Analytical Impulse Values.................................24

Figure 16. Average Cm Per Consecutive Pulse.........................................................26

Figure 17 Shadowgraph Shock wave of a .005" thick POM sample...............................27

Figure 18. Exhaust Velocity for POM Samples of Thickness .005", .010" and .020".....28

Figure 19. Progression of .005" sample Shockwave. A.) Pre-pulse, B.) Initial burn, C.) formation of initial bubble, D, E and F further expansion of shock..............................29

Figure 20. Progression of .010" sample Shockwave. A.) Pre-pulse, B.) Initial burn, C.) formation of initial bubble, D, E and $\mathrm{F}$ further expansion of shock...............................30

Figure 21. Progression of .020" sample Shockwave. A.) Pre-pulse, B.) Initial burn, C.) further burning, D, E and F expansion of shock. 
Figure 22. Load Cell Calibration plots of 0.1 Gram Pendulum at 4565 and 90 degrees. .45

Figure 23. Load Cell Calibration plots of 0.2 Gram Pendulum at 6590 and 45 Degrees. 46 


\section{List of Tables}

Table 1. Different Types of Laser Propulsion Systems (Bohn, 2008)...............................

Table 2. Laser and Load Cell Parameter.......................................................................... 11

Table 3: Experiment Constants and Variables...........................................................18

Table 4. Average Force Per Consecutive Pulse for Sample Thicknesses .005", .010" and .

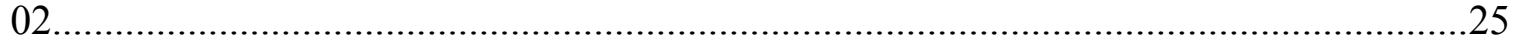

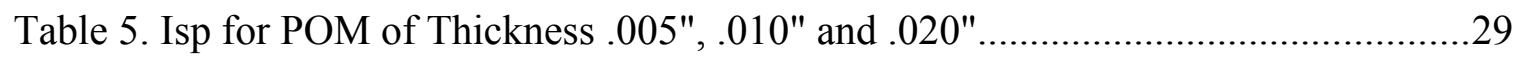

Table 6. Ablation Efficiency Parameter for .005", .010" and .020" Thick Samples.........31

Table 7. POM vs. Previous Experiments Using Different Polymers.................................32

Table 8. Load Cell vs. Analytical Results at 45, 65, 90 Degrees for a 0.1 Gram Pendulum

Table 9. Load Cell vs. Analytical Results at 45, 65, 90 Degrees for a 0.2 Gram Pendulum 


\section{Introduction}

Laser propulsion has been a field of research since original thinkers started planning on using laser technologies as far back as the 1950s. Today, laser propulsion is separated into three types (as shown in Table 1), but for this paper the focus will be on indirect pulsed lasers (Bohn, 2008).

Table 1. Different Types of Laser Propulsion Systems (Bohn, 2008)

\begin{tabular}{|ccc|}
\hline Type & Mechanism & Example \\
\hline Direct & Photon Pressure/lmpulse & Sail \\
\hline Indirect & CW Conversion to Electricity & $\begin{array}{c}\text { Photovoltaic Cell } \\
\text { Thermal Cycle Engine } \\
\text { Jet Engine }\end{array}$ \\
\hline Indirect Pulsed & $\begin{array}{c}\text { Blast Wave } \\
\text { Hybrid }\end{array}$ & $\begin{array}{c}\text { Chemical Reaction + Laser } \\
\text { Heating }\end{array}$ \\
\hline
\end{tabular}

The primary issue with early attempts at using lasers for propulsion was that laser hardware was large and cumbersome and required a large amount of power to operate. Meanwhile, the available output of the lasers was still in the kilowatt region while researchers needed gigawatt and terawatt power lasers, which are now available today. Most laser propulsion ideas from the 1980s have been based around large, high-powered, land-based lasers providing energy to lift a vehicle from the ground into orbit. There are many complications associated with such systems, such as weather conditions (which need to be clear to limit the dispersion of the beam), controlling the beam to keep it on target, and providing enough power for the duration of the liftoff event (Cook, 2008). Recently, with improvements in diode laser technology, the size and power requirements 
for these efforts are dropping dramatically. This puts laser propulsion on the list of systems that could potentially go into orbit on satellites.

A growing field in research today is in the use of nano/pico satellites in a constellation, providing for low cost deployment and development costs. One of the primary issues that arises from utilizing such small satellites is that most modern propulsion systems are not designed for a small package. Another issue is that the nano/pico satellites for this configuration are destroyed once their orbit decays. If a system could be developed that was small, light weight, and capable of providing a reasonable amount of thrust and specific impulse (Isp), that type of constellation system could become more universally recognized as a viable means of using satellite laser technology for applications like propulsion.

Another technology currently in use is the pulsed plasma thruster (PPT). The PPT works along the same principles of a laser ablation thruster, where plasma is generated using an electrical source and the resulting plasma plume creates the desired thrust. The fuel material typically used with the PPT is the polymer polytetrafluoroethylene(PTFE) where the electrical spark ablates the PFTE, creating the plasma plume. Part of the PPT design involves harnessing the effects of this Lorentz force by using a magnetic field to shape and accelerate the plasma plume so that it exits in a focused direction. Alternatively, a laser ablation thruster eliminates the need to provide a magnetic field to accelerate the plasma

In this thesis, it is proposed that a high power solid state diode laser in the $5-25 \mathrm{~W}$ 
power range and a pulse range of $200 \mu$ s to milliseconds (Urech, Lippert, Phipps, Wokaun, 2007) operating in an ablative function in the near IR range will provide enough thrust for station-keeping for a small satellite. Many different materials, ranging from metals to polymers, have been used as a fuel for laser ablation propulsion. Due to the low power nature of the laser in this research, the material of choice will be a polymer; the laser does not have enough power to successfully convert a metal into plasma, which requires lasers in the mega and terawatt power ranges (Horisawa, Kimura, 2002). Polyoxymethelyne (POM) in particular will be used in this experiment because much work has been done studying the material characteristics of POM and how it behaves under laser ablation. Other polymers such as PTFE can be used; it would only be a matter of using a laser with the correct wavelength to try to maximize the energy absorbed by the material from the laser.

There is a large amount of research being conducted on how to design efficient and inexpensive ways to accurately deploy a swarm of nanosatellites into a low-earth orbit. One project is the SWORDS (Soldier-Warfighter Operationally Responsive Deployer) project. The goal of this project is to quickly and accurately deliver a $25 \mathrm{Kg}$ payload to a $750 \mathrm{Km}$ orbit with a 28.5 degree inclination. An additional goal is to keep the cost of each launch at $\$ 1$ million (USASMDC, 2014). The mission of the SWORDS project is to give a warfighter the ability to deploy a satellite network with launch-ondemand capabilities. This would reduce the cost of maintaining a nanosatellite network. A second company, Ventions, working in conjunction with DARPA and NASA, is 
creating SALVO (Small Air Launch Vehicle to Orbit), a method capable of delivering 5 Kg from a fighter aircraft to low earth orbit ("DARPA Developing”, 2014). The initiative behind this project is an Airborne Launch Assist Space Access (ALASA) test platform to help understand the mechanics behind air launching in particular ("Boeing to Design”, 2014).

A considerable amount of time and money is being spent on developing more efficient ways of launching nano/pico satellites into orbit. With this in mind, it is only practical that the next step will be to enable the small satellites to have station-keeping abilities, reducing the cost of continually having to replace satellites as they fall from orbit as well as the cost of the launch systems needed to place new satellites into orbit.

This increased interest in using nano and pico satellites suggests the need to design a micro-thruster that utilizes laser ablation propulsion. The emphasis of this paper is not to design such a micro-thruster but, rather, to test the behavior of POM as an ablation fuel. For the sake of clarifying the mechanical functions of a thruster, a basic micro-thruster design is, however, described. The primary benefits of micro-thrusters are many: they are inexpensive, have low power requirements, and make efficient use of fuel. Likewise, the constraints of a micro-thruster are basic: they are small, light weight, and must meets minimum mission thrust requirements.

A design put forward by Urich, Lippert, Phipps, and Wokaun (2007) uses a substrate that is transparent to the laser wavelength, and a polymer fuel is deposited as a thin film onto the substrate. The laser is then fired through the substrate, thus ablating the 
polymer, which generates the plasma plume, producing the desired thrust. One obvious innovation on this design is to use a tape spool to store the substrate with the polymer film and, as the laser ablates the polymer off the substrate, have the tape system provide new material to ablate. This is demonstrated in Figure 1. This system works because of the behavior of the laser ablation mechanism, especially the forward plasma acceleration mode, which is discussed in further detail in the next section.

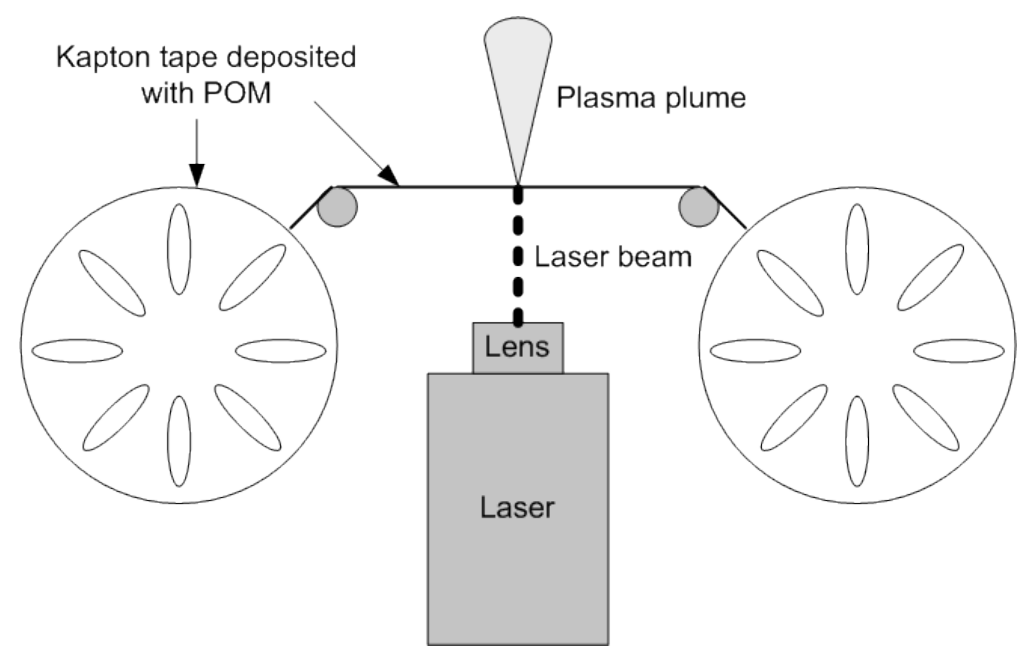

Figure 1: Micro-Thruster Schematic

With this micro-thruster, the primary size constraint is the size of the laser diode. For instance, a FAP 600, currently available from Coherent Inc., measures roughly 1.25 " $\mathrm{x} 2.5$ " $\mathrm{x} 1$ ". This is a pre-built, ready-to-use laser diode that only needs cooling and power to operate. This brings up another advantage of the solid state diode laser, they require typically only 2.5 Volts and a high current. This allows the use of an ultracapacitor that could be charged over time by solar panels to provide the high current 
needed by the laser. The tape spool size is determined by the mission length and material used as a fuel, and the tape width would be determined by further experimentation. A thruster of this type could easily fit into a $10 \times 10 \times 10 \mathrm{~cm} 1 \mathrm{~kg}$ cubesat.

\section{Method}

\section{Laser Ablation Mechanism}

The mechanisms by which laser ablation creates thrust occur in three stages: 1) electron emission through the ponderomotive force of a laser pulse, 2) ion acceleration through Coulomb explosion, and 3) evaporation through phase explosion. On a reflective solid surface, these forces are generated back at the direction from which the laser pulse originated. This means that, for the best possible results, the laser must be pulsed. When the laser is pulsed fast enough, the plasma plume does not interfere with the laser pulse and the duration can be short enough that the conductive heat transfer from the pulse into the material is at a minimum (Horisawa et al., 2002).

There is a second mode of reflective plasma acceleration. This is the forward plasma acceleration mode (Figure 2), which occurs when the incident laser pulse hits a target material that is thin enough that the electron emission occurs through the opposite side of the material and all three stages of the laser ablation occur (Horisawa et al., 2002). This is of great interest to the propulsion community in that it does not require a complicated setup to place the laser in a position opposite to the plasma plume, potentially blocking the thrust from being generated. For the sake of this research, reflective plasma acceleration will be used to simplify the setup of the experiment. 


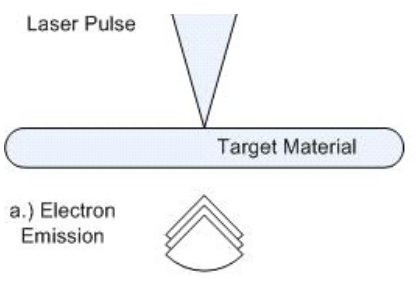

Electrons

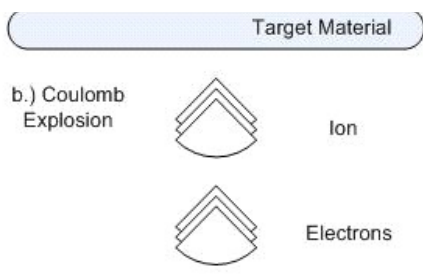

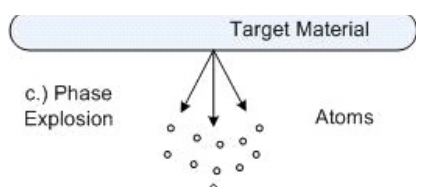

Ion

Electrons

Figure 2. Forward Plasma Acceleration - a.) Electron Emission, b.) Coulomb Explosion, and c.) Phase Explosion

\section{Fuel Material}

The material used in this experiment is polyoxymethelyne (POM). This polymer comes in two basic forms: homopolymer and copolymer (as illustrated in Figure 3).

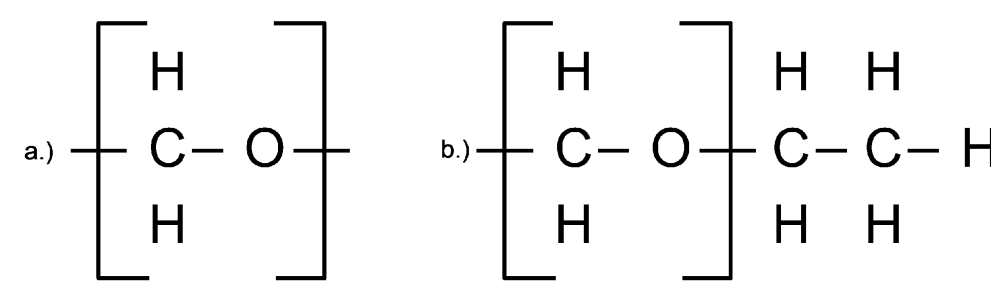

Figure 3. Chemical Structure of POM a.) Homopolymer and b.) Copolymer

This polymer is widely available commercially in both the homopolymer form under names such as Delrin ${ }^{\mathrm{TM}}$, Sustarin $\mathrm{H}$, and Tecaform and, in its copolymer form, Acetron, Hostaform, and Duracon, to name a few. The main difference among them to be noted for the purpose of this experiment is the performance difference between homopolymer and copolymer POM. Homopolymer is known to rapidly degrade in an unzipping manner, releasing the formaldehyde monomer (Sinkho, Sasoh, 2011).

Original work was done with POM and a $\mathrm{CO}_{2}$ laser that had a wavelength of 10.6 $\mu \mathrm{m}$. From this work, it was shown that, theoretically, POM requires temperatures of 
$5000 \mathrm{~K}$ to combust whereas, in actual laboratory experiments, temperatures of $500 \mathrm{~K}$ were sufficient for POM combustion. This incongruity is puzzling but is beneficial to the purpose of lowering the amount of power that the laser requires, making POM an ideal possible nano/pico satellite fuel. Another important factor to take into consideration is the absorption coefficient $(\alpha)$. For a POM homopolymer and a $\mathrm{CO}_{2}$ laser, the $\alpha$ is around $5.5 \times 10^{5} \mathrm{~m}^{-1}(10.6 \mu \mathrm{m})$, using Equation 1 and the following values: $\lambda=980 \mathrm{~nm}, \mathrm{n}=1.35$ and $\mathrm{k}=.12$ (real and imaginary refractive index) (Sinkho et al., 2011).

$$
\alpha=\frac{4 \pi n k}{\lambda}
$$

This yields $\alpha=2.06 \times 10^{6} \mathrm{~m}^{-1}(980 \mathrm{~nm})$, which is greater than what is yielded from a $\mathrm{CO}_{2}$ laser, providing for a more efficient use of the energy imparted by the laser pulse for the wavelength.

Recognizing that POM breakdown starts occurring around $500 \mathrm{~K}$ permits the reactants produced of importance, Figure 4 shows the gasses produced by POM over a temperature range (Sinkho et al.,2011). 


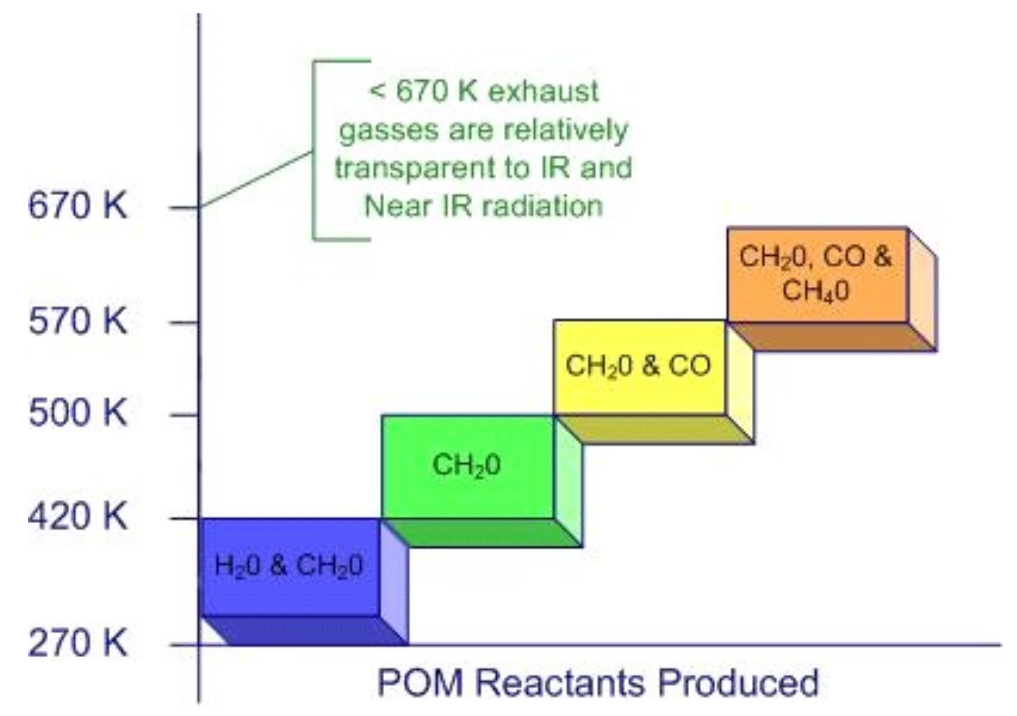

Figure 4. Reactants Produced by POM between $270-670$ K

It is important to note that water in the $270-420 \mathrm{~K}$ temperature range is a good absorber of IR and near-IR wavelengths, which could potentially reduce the amount of energy incident to the surface from the laser beam. The rest of the products, though, are all nearly transparent to the same wavelength, showing that if the laser pulse can quickly heat up the target and minimize the length of time that water vapor is produced, the interference of the reactants produced will be low (Sinkho et al., 2011).

For the purpose of this experiment, the version of POM used will be the DuPont variant known as Delrin ${ }^{\mathrm{TM}}$, in three different thicknesses: .005", .010", and .020." It has been found that the thickness of the ablation fuel makes a noticeable difference in the amount of thrust generated (Horisawa, Sumida, Yonamine, Funaki, 2013). The reasons for choosing Delrin ${ }^{\mathrm{TM}}$ are that it is a commercially available material that can be easily 
manufactured and that it is a homopolymer version of POM, allowing us to take advantage of its tendency to degrade in a rapid, unzipping manner.

\section{Experimental Setup}

\section{Initial setup of the experiment test area.}

For the experiment, a CNI FC-W-980-20 Diode laser was acquired. This laser system was chosen for the $980 \mathrm{~nm}$ wavelength; it has built-in $5 \mathrm{KHz}$ TTL (Transistor Transistor Logic) modulation and outputs $20 \mathrm{~W}$ with a $85 \mathrm{~mm}$ focal distance (Figure 5). The laser has the ability to monitor its operating temperature and output current, which allows for consistent sample-to-sample runs. The TTL modulation is controlled by a Board Tech pulse generator that has the capacity to send pulses at a rate of $20 \mathrm{MHz}$, which allows for the control of high or low logic, pre-pulse pause, the length of the pulse, the time between pulses, and the number of pulses. The impulse imparted to the system will be measured using a LCL-113G thin beam load cell with a mounting surface for the POM samples (Table 2).

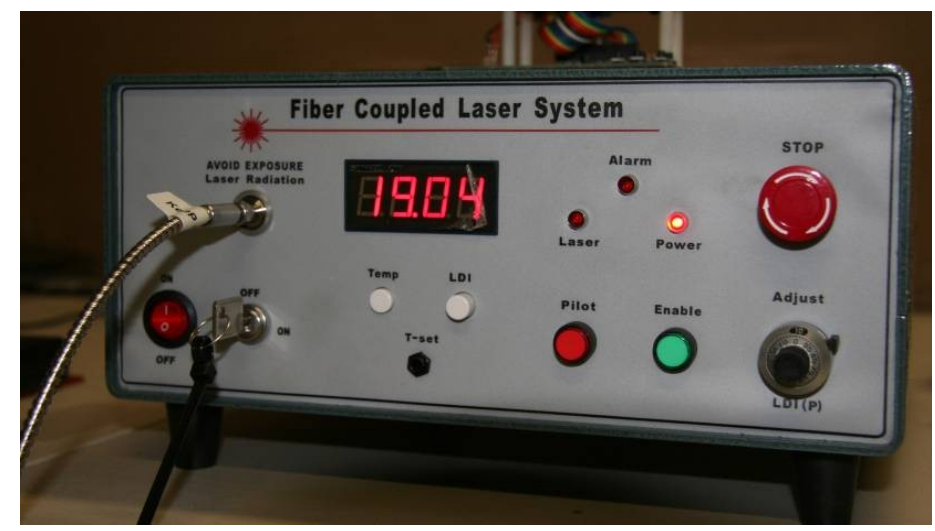

Figure 5. CNI-FC-W-980-20 
Table 2. Laser and Load Cell Parameter

\begin{tabular}{|c|c|c|c|}
\hline \multicolumn{2}{|c|}{ CNI-FC-W-980-20 Parameters } & \multicolumn{2}{|c|}{ LCL-113G Specifications } \\
\hline Power & 20 Watt & Reference V & $5 \mathrm{Vdc}$ \\
\hline Wavelength & $980 \mathrm{~nm}$ & Rated Output & $2 \mathrm{mV} / \mathrm{V}$ \\
\hline & & Compensated & \\
\hline Modulation & $5 \mathrm{KHz}$ TTL & Temperature & $20-120^{\circ} \mathrm{F}$ \\
\hline Spot Size & & Full Scale & \\
\hline (diameter) & $.75 \mathrm{~mm}$ & Deflection & $0.010-0.050^{\prime \prime}$ \\
\hline Focal Distance & $85 \mathrm{~mm}$ & & \\
\hline
\end{tabular}

A Texas Instruments Amplifier with a rated output of $2 \mathrm{mV} / \mathrm{V}$ was utilized to amplify the output signal of the LCL-113G. To this end, an INA125P, which has the ability to increase the gains of the signal by 10,000 , was utilized. For this experiment, a $10 \mathrm{Ohm}$ resistor was used to set the gain of the INA125P to 6000, as shown in Figure 6.

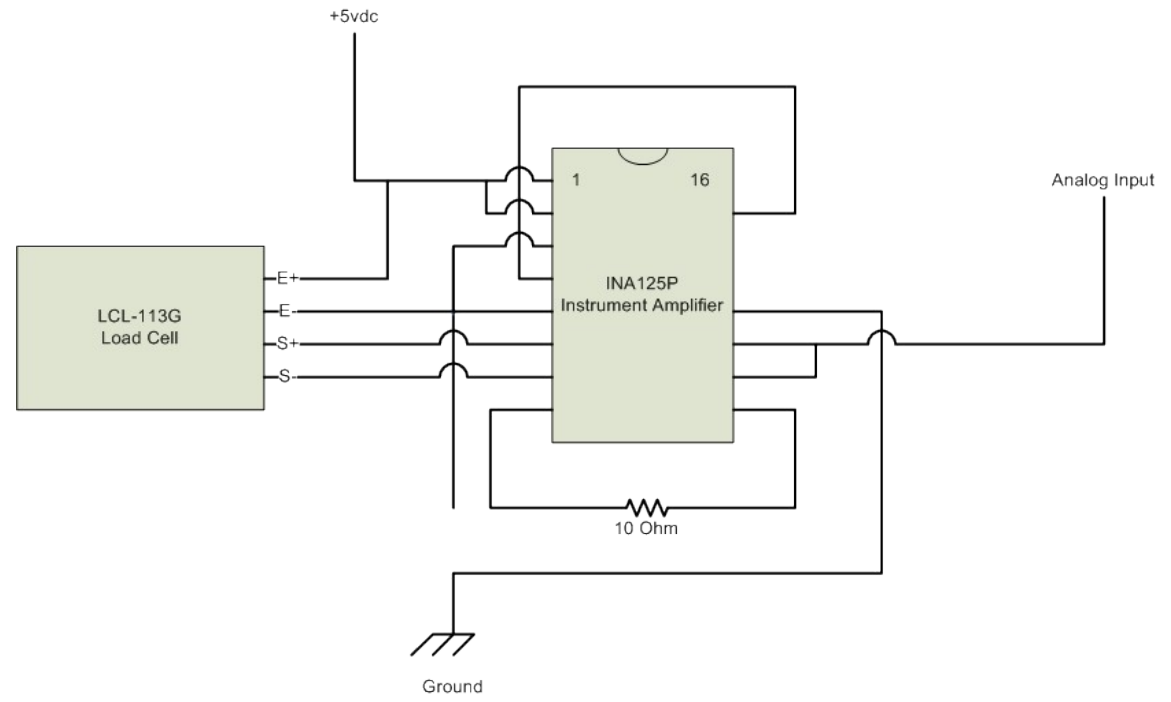

Figure 6. TI INA125P Wiring Schematic 
The experiment was conducted in a 15 in. Hg vacuum chamber. The chamber was constructed of $1 / 2$ " acrylic with a rail that had a thin beam load cell mounted to it inside the chamber to measure the impulse of the system (Figure 7). The load cell was attached using sharp, square-edged metal blocks, which was essential to maintaining the desired sensitivity of the system. A mounting plate was attached to the bottom of the load cell, which extended the contact surface of the load cell to the center to achieve the desired stress and strain relationship needed for high sensitivity (Figure 8). Performing the experiment in a vacuum negated any effects of air combusting during the plasma acceleration event, adding to the total thrust of the system. To measure the shockwave velocity and determine the thrust, impulse coupling coefficient $(\mathrm{Cm})$, and the Isp, a combination of a load cell, shadowgraph imaging, and a high frame rate camera was used (Figure 9).

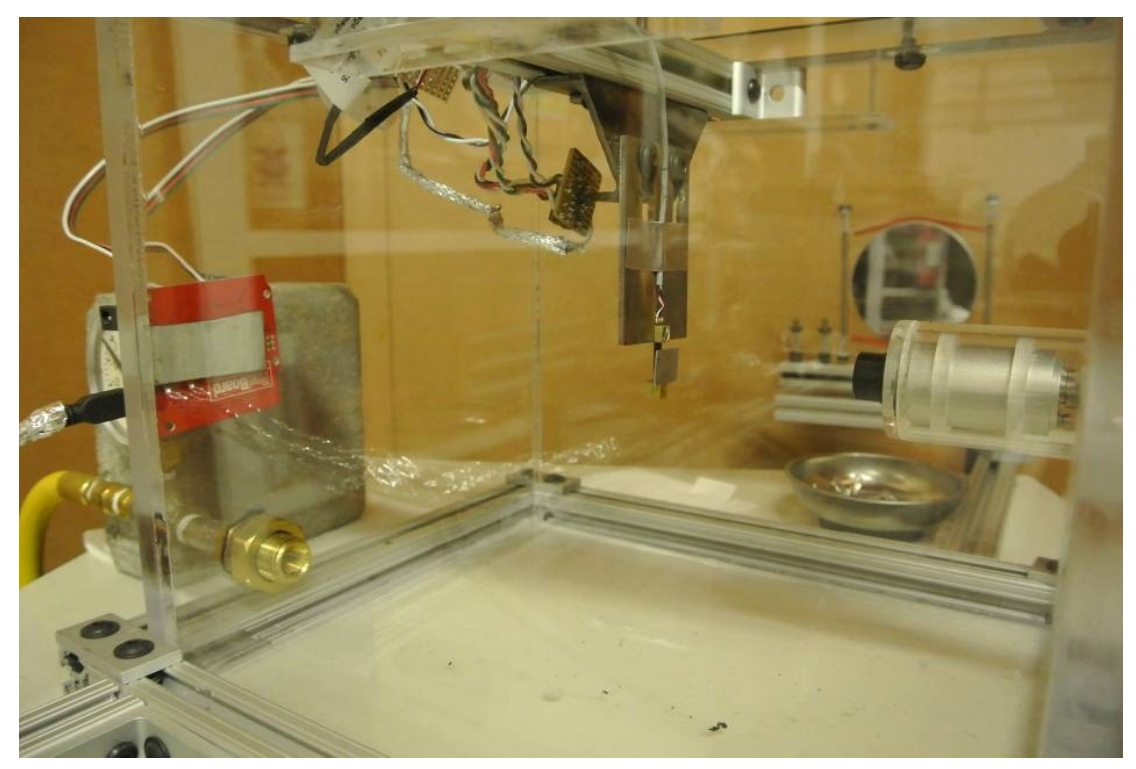

Figure 7. Vacuum Chamber 

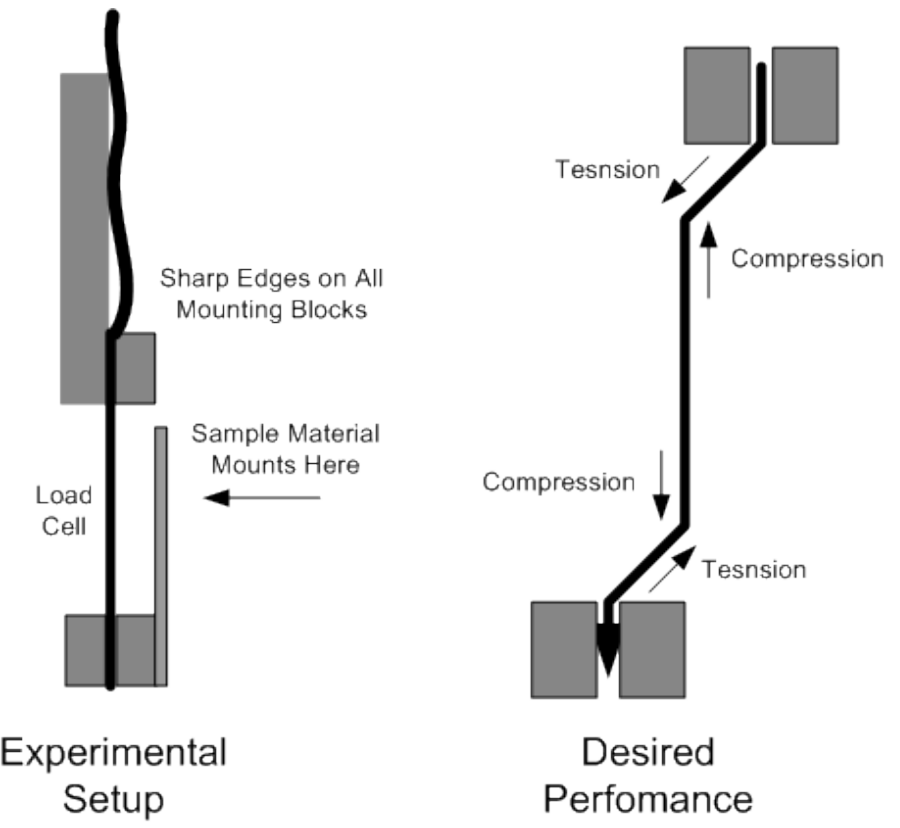

Figure 8. Diagram of Load Cell Setup

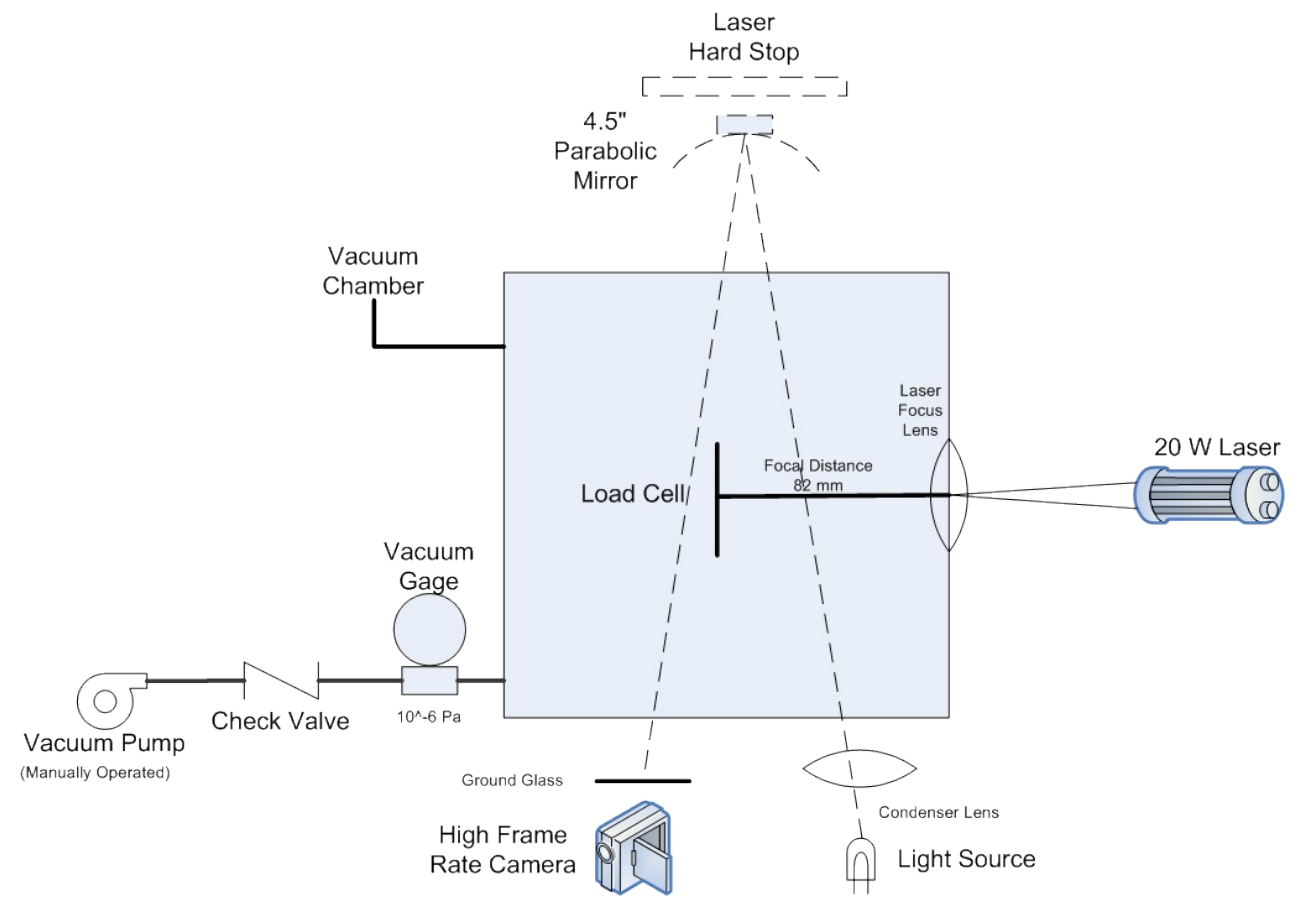

Figure 9. Experiment Layout 
The load cell measures the load on the system imparted by the laser. To calibrate the load cell and relate it to the Impulse, the sensor readings needed to be scaled to the impulse imparted to the system. To achieve this, 2 masses weighing .1 gram and .2 grams, respectively, attached to a pendulum made from $.25 \mathrm{~mm}$ diameter monofilament were dropped onto the sensor from 3 different angles. The values of the impulses were then calculated using Equation 2, where $\mathrm{m}=$ mass, $\mathrm{g}=$ gravity, and $\mathrm{L}=$ length from the center of the mass to the rotation axis.

$$
I=\sqrt{2 m g L(1-\cos (\theta)} \quad(\mathrm{N} \cdot \mathrm{S})
$$

These values were then compared to the root mean square (RMS) of the signal from the load cell and the appropriate conversion factor was calculated for the impulse RMS estimator.

\section{Setup of the shadowgraph imaging.}

The second measurement method used to calculate the Isp (sec) was shadowgraph imaging. The shadowgraph system consists of a light source, a $75 \mathrm{~mm}$ x $50 \mathrm{FL}$ aspheric condenser lens, one 4.5" f/8 parabolic mirror, a piece of ground glass, and the $1200 \mathrm{fps}$ video camera (Figure 11). The light source is a point light shone through a .22" aperture onto a condenser lens that collimates the light and shines it onto the parabolic mirror. 


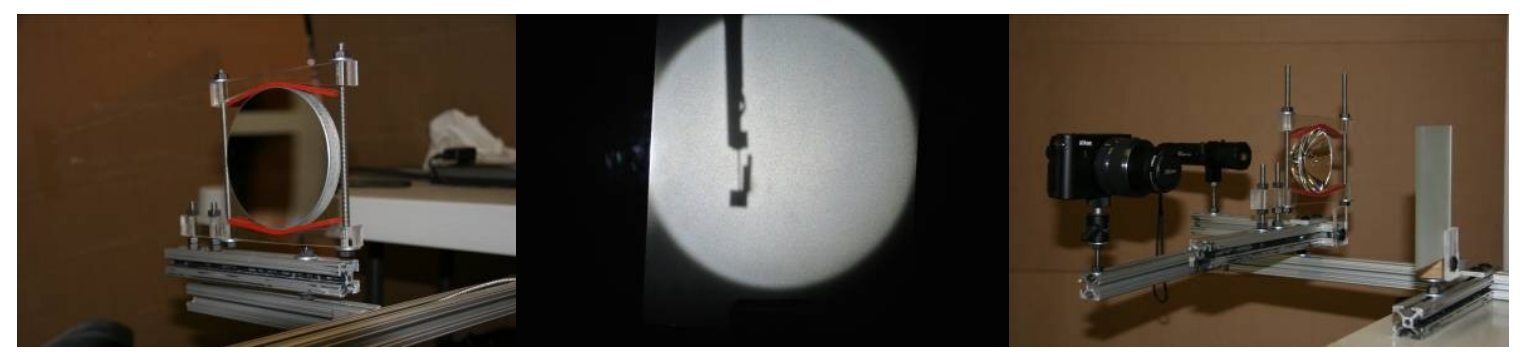

Figure 10. Shadowgraph Optics

The parabolic mirror takes the partially collimated light, collimates it more, and reflects it through the observation field and onto the ground glass. Changes in density refract the light as it passes through the test region, casting a shadow of the resulting shockwave. The ground glass must be placed at the focal distance of 35.4" from the mirror for the best image clarity. The shadowgraph image projected and transmitted onto and then through the ground glass is then captured by the camera. The camera being used is a Nikon $1 \mathrm{~J} 1$, which captures video in 5 second clips at $1200 \mathrm{fps}$ and a resolution of 120P (Figure 10). In this system, the shockwave of the plasma plume can be imaged, its exhaust velocity can be measured using the 1200 fps camera, and its shockwave can be tracked frame-by-frame, which gives the time dependent position of the shockwave. 

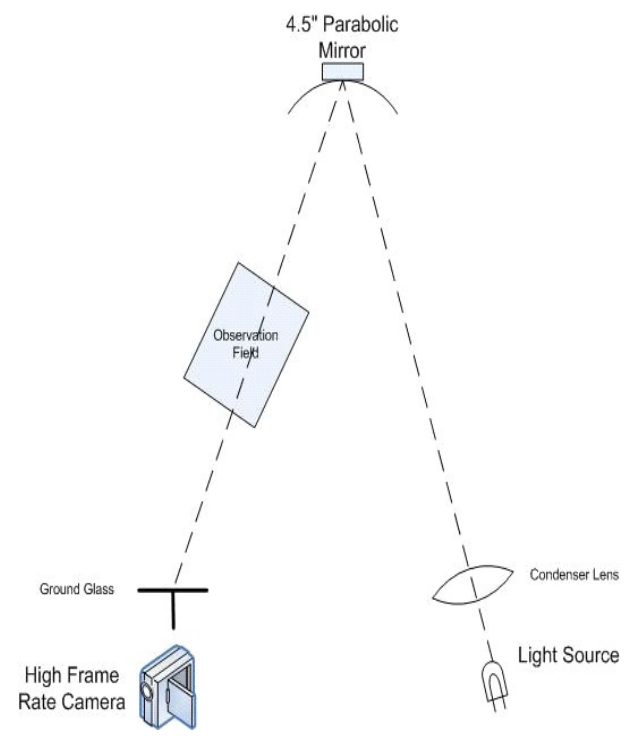

Figure 11. Shadowgraph Setup

\section{Performance measurements.}

Equation (4) defines the motion of the pendulum, where $\Omega$ is the angular

frequency, $\omega_{0}$ is the un-damped angular frequency, and $\beta$ is the damped constant.

$$
\begin{aligned}
& \frac{d^{2} \theta}{d t^{2}}+2 \beta \frac{d \theta}{d t}=\Omega_{0}^{2} \theta=0 \\
& \theta(t=0)=0 ; \frac{d \theta}{d t}(t=0)=\omega_{0}
\end{aligned}
$$

The solution to the differential equation and the initial condition is

$$
\begin{gathered}
\theta(t)=\frac{\omega_{0}}{\Omega} e^{-\beta t} \sin (\Omega t) \\
\Omega^{2}=\Omega_{0}^{2}-\beta^{2}
\end{gathered}
$$

According to Gualini, Khan, and Zulfiqar (2006), equations 6 and 7 can be used to obtain the $\mathrm{Cm}$ : 


$$
C m=\frac{m \Delta v}{E}=\frac{2 m \omega_{0} r}{E}
$$

where $\mathrm{m}$ is the mass ejected, $\Delta \mathrm{v}$ is the average velocity of the mass, and $\mathrm{E}$ is the laser energy (Rinaldi et al., 2011).

Using Equation 7 and making some substitutions, the following formula can be used for finding the $\mathrm{Cm}$ :

$$
C m=\frac{I(N \cdot s)}{E(W \cdot s)}=\frac{F(N)}{P(W)}
$$

where, notably, $\mathrm{F}$ is the thrust into the system and $\mathrm{P}$ is the power imparted to the system. After measuring the plume velocity of the plasma event, the Isp can be calculated.

$$
I s p=\frac{v_{E}}{g}
$$

A final point of interest is also the ablation efficiency parameter $\eta_{\mathrm{AB}}$. This is the efficiency of the conversion of the laser energy onto the target into kinetic energy in the exhaust (Urech et al., 2007) and is defined as:

$$
2 \eta_{A B}()=C m \cdot v_{E} \quad(\%)
$$

This parameter enabled us to determine the efficiency of the different thicknesses of the 3 different samples to help determine the optimum thickness range required for the fuel to provide the best amount of thrust. 


\section{Experiment Constants and Variables}

The following sections cover the constants in this experiment. They include the hardware used in the experiment as well as some decisions for this research based on a study of previous experiments. The independent variables were chosen based on the findings of past experiments but also with reference to constraints of the materials available. The dependent variables enabled the calculation of the results for the desired values of thrust, Isp, Cm, and ablation efficiency.

Table 3: Experiment Constants and Variables

\begin{tabular}{|c|c|c|c|c|c|}
\hline \multicolumn{3}{|c|}{ Experiment Constants } & \multicolumn{2}{|c|}{ Independent Variables } & Dependent Variables \\
\hline Laser & $\begin{array}{c}\text { Power } \\
\text { Wavelength } \\
\text { Spot Size } \\
\text { Focal Distance }\end{array}$ & $\begin{array}{l}20 \mathrm{Watt} \\
980 \mathrm{~nm} \\
.75 \mathrm{~mm} \\
85 \mathrm{~mm}\end{array}$ & \multirow[t]{3}{*}{ Fuel Thickness } & $\begin{array}{l}.005 " \\
.010 "\end{array}$ & Shockwave Velocity \\
\hline Fuel Material & \multicolumn{2}{|c|}{ Polyoxymethelyne } & & \multirow{2}{*}{$.020 "$} & \multirow[t]{2}{*}{ Thrust } \\
\hline Pulse length & .010 & & & & \\
\hline
\end{tabular}

\section{Experiment constants.}

The laser parameters, shown previously in Table 2, were a set constant, with the laser running at its full power of 20 Watts. It is important to note that this laser does not produce a true pulse. A true-pulsed laser has the ability to impart more power at the initiation of the pulse and then drop rapidly back to the specified energy of the laser pulse. This characteristic is highly desirable because it allows for a weaker laser to initiate a plasma event and maintain the plasma event with relatively little energy. Due to budget constraints, the laser chosen for this experiment was a modulated laser using TTL 
modulation. This laser, as opposed to a pulsed laser, behaves in a square wave manner. The power never peaks above the chosen setting of the laser. Rather, unlike the pulsed laser, which peaks at initiation, the modulated laser has a slight delay before reaching full power. This means that the power of the laser required to achieve the same results is greater for a modulated laser than a pulsed laser (Figure 12). Also, as part of the experimental constants, all of the measurements were taken in a vacuum chamber to reduce the effects of combustion in the test chamber but also, and primarily, as a means to remove water vapor from the test area. Water vapor is known to block light in the IR region. Finally, the pulse length was constant throughout the experiment to ensure that the amount of energy being lased onto the surface would be consistent from sample to sample.

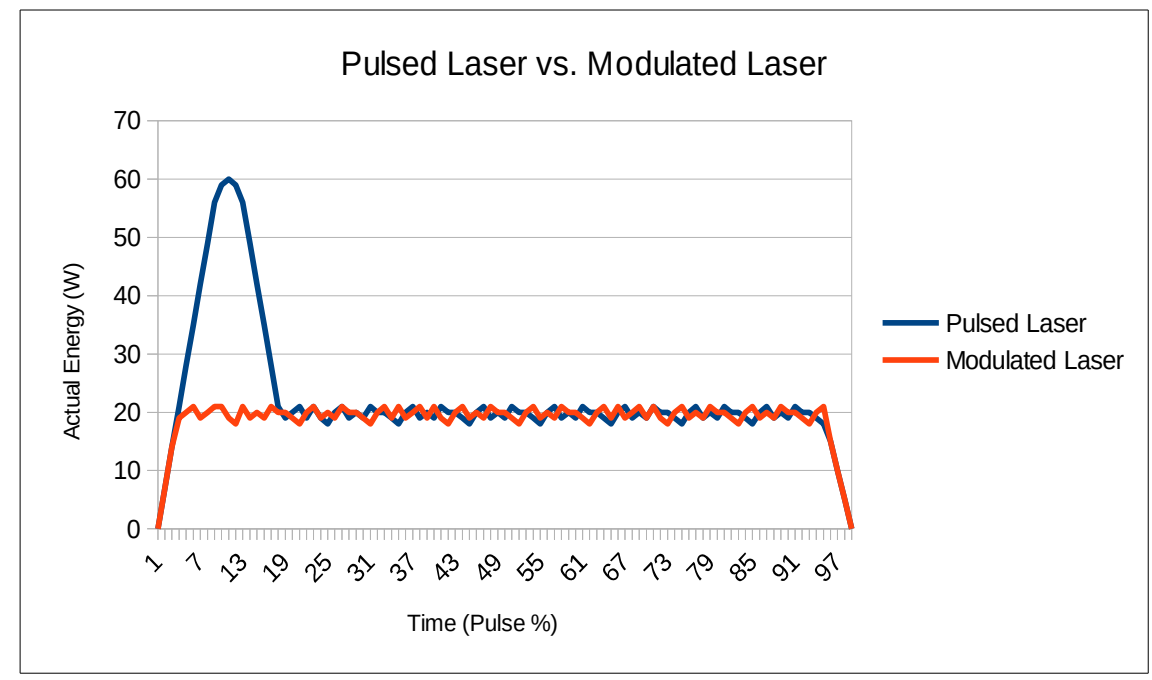

Figure 12. Pulsed vs. Modulated Laser 


\section{Independent variables.}

The independent variable of the experiment was the varied thickness of the target material. This allowed for the correlation of the efficiency of the system to impart the energy of the laser into the material and revealed how the thickness of the material affects

the plume by absorbing the energy and distributing it across the sample. The desired goal was to determine the best thickness to begin further experimentation if the POM proved to be a desirable fuel.

The three thicknesses chosen were picked due to their availability. Natural POM can be acquired easily through material supply stores in films of the following thicknesses: .005", .010", and .020". Each film thickness is 2 times thicker than the previous one and this is a feature of interest when comparing the achieved performance.

\section{Dependent variables.}

The shockwave velocity is the first dependent variable to be analyzed. It was recorded for each of the thicknesses of the POM fuel samples and comparisons were made across the samples thicknesses as well between the numbers of single pulses lased onto the target. One important characteristic was how the shockwave velocity changes the more pulses that the POM receives. The shockwave velocity was measured using the shadowgraph and camera system, as described in previous sections.

Thrust was the second dependent variable. The thrust measurements are the result of the efficiency of the laser ablating the fuel material. Again, as with the shockwave velocity, the comparisons of the sample thicknesses and number of pulses from the laser 
were conducted. The thrust measurements were achieved using the load cell and impulse measurement system, as described in previous sections.

\section{Experimental Procedure}

\section{Safety.}

Since this experiment used a class 4 Infrared 20 Watt laser, which has the potential to cause serious harm and injury to operators and bystanders if misused, certain safety protocols were implemented. The laser has a main power switch that enables the power supply and cooling systems, a key interlock, an enable switch, and an emergency cutoff switch.

All personnel wore proper laser eye wear whenever the key interlock was engaged.

No personnel stood with their eyes level with the horizontal plane of the laser emitter when the key interlock was engaged.

A hard stop was placed along the path of the laser beam to interrupt the beam in the event the laser burned through the target and to prevent the laser beam leaving the test platform.

Safety shields surrounded the test area to protect the area from errant reflections.

The laser operator kept the emergency cutoff switch within arms length whenever the laser was enabled.

Unnecessary personnel stayed out of the test area, which was designated by floor lines and reflection shields, whenever the laser was enabled. 


\section{Procedure.}

The steps diagrammed in Figure 13 outlined the general process followed during the running of the experiment. It is important to note that every run began with verifying that all the safety protocols were being followed. The experiment was run in the following order:

$.005 "$ thick POM sample

10 samples, 5 pulses each, .3 seconds apart

.010 thick POM sample

10 samples, 5 pulses each, .3 seconds apart

$.020 "$ thick POM sample

10 samples, 5 pulses each, .3 seconds apart

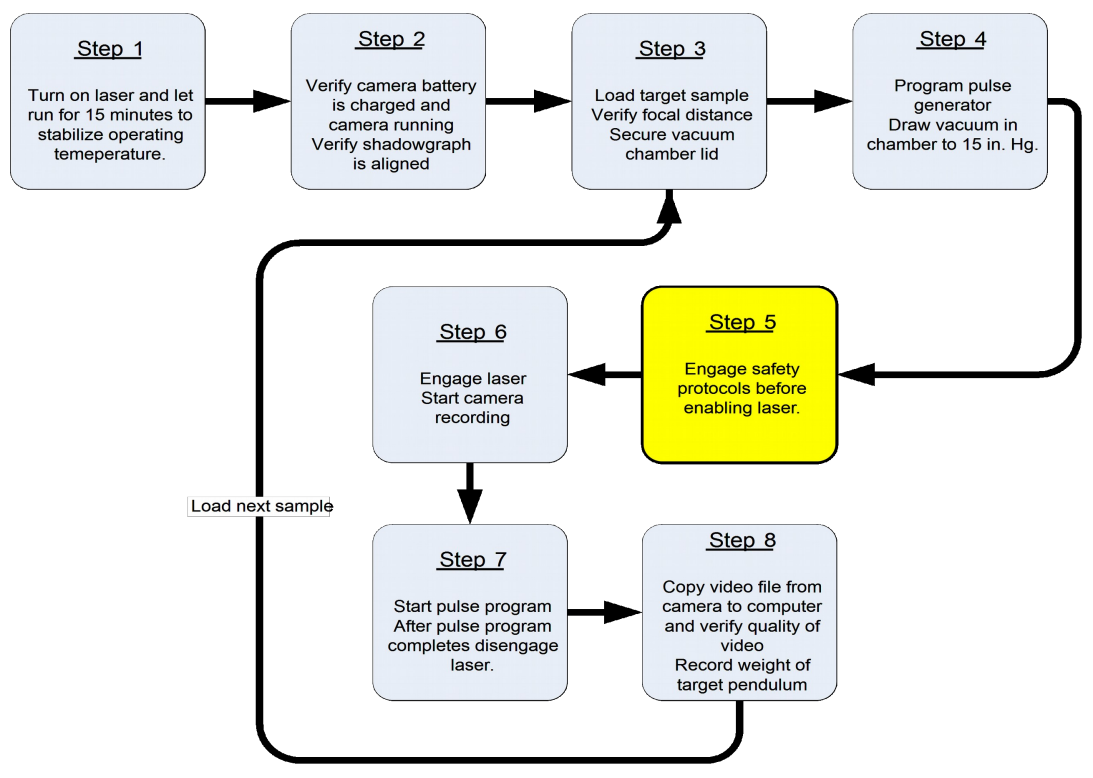

Figure 13. Experiment Process 
Figure 14 shows a sample of the log used for each sample. The primary purpose of the log was to verify that all of the data files for the load cell and the video files were collected and named appropriately to ensure that the correct data was correlated to the correct samples as the experiment moved forward.

\begin{tabular}{|c|c|c|c|c|c|c|c|c|c|c|c|c|c|}
\hline $\begin{array}{c}\text { Sample } \\
\text { \#. Pulse } \\
\text { Count }\end{array}$ & Date & Time & $\begin{array}{l}\text { Laser } \\
\text { Temp }\end{array}$ & $\begin{array}{c}\text { Sample } \\
\text { Thicknes } \\
\text { s }\end{array}$ & $\begin{array}{l}\text { Chamber } \\
\text { Vacuum } \\
\text { Pressure }\end{array}$ & $\begin{array}{c}\text { Target } \\
\text { Mass }\end{array}$ & Data File & $\begin{array}{c}\text { Video } \\
\text { File }\end{array}$ & $\begin{array}{c}\text { Distance } \\
(\mathrm{mm})\end{array}$ & $\begin{array}{c}\text { Start } \\
\text { Frame }\end{array}$ & $\begin{array}{c}\text { Stop } \\
\text { Frame }\end{array}$ & $\begin{array}{c}\text { No. } \\
\text { Frames }\end{array}$ & $\begin{array}{c}\text { Shock } \\
\text { Wave } \\
\text { Velocity } \\
(\mathrm{m} / \mathrm{s})\end{array}$ \\
\hline 1.1 & & & & $.005 "$ & & & & & 10 & & & & \\
\hline 1.2 & & & & $.005^{\prime \prime}$ & & & & & & & & & \\
\hline 1.3 & & & & $.005^{\prime \prime}$ & & & & & & & & & \\
\hline 1.4 & & & & $.005^{\prime \prime}$ & & & & & & & & & \\
\hline 1.5 & & & & $.005 "$ & & & & & & & & & \\
\hline
\end{tabular}

Figure 14. Sample Experiment Log (Data Shown in Appendix)

\section{Results}

\section{Load Cell Data}

The load cell data were collected using an ADC converter with an output over serial; this data was then read, displayed, and saved in Matlab ${ }^{\mathrm{TM}}$. The sensor, due to its small size and low gram sensitivity, was very sensitive to changes in temperature, but even with temperature change the linearity of the output of the sensor remained the same. It was necessary to adjust the offset, bringing the sensor back to zero. To correlate the sensor data to the impulse input into the system, the impulse from the pendulum was measured by the sensor and recorded using Matlab ${ }^{\mathrm{TM}}$, and then the actual impulse values were used to adjust the sensor values to match the correct impulse. The sensor values, when normalized with the analytical values, are nearly identical (as seen in Figure 15). 
Using this information, a scaling factor was calculated to scale the sensor data, matching them to the analytical data.

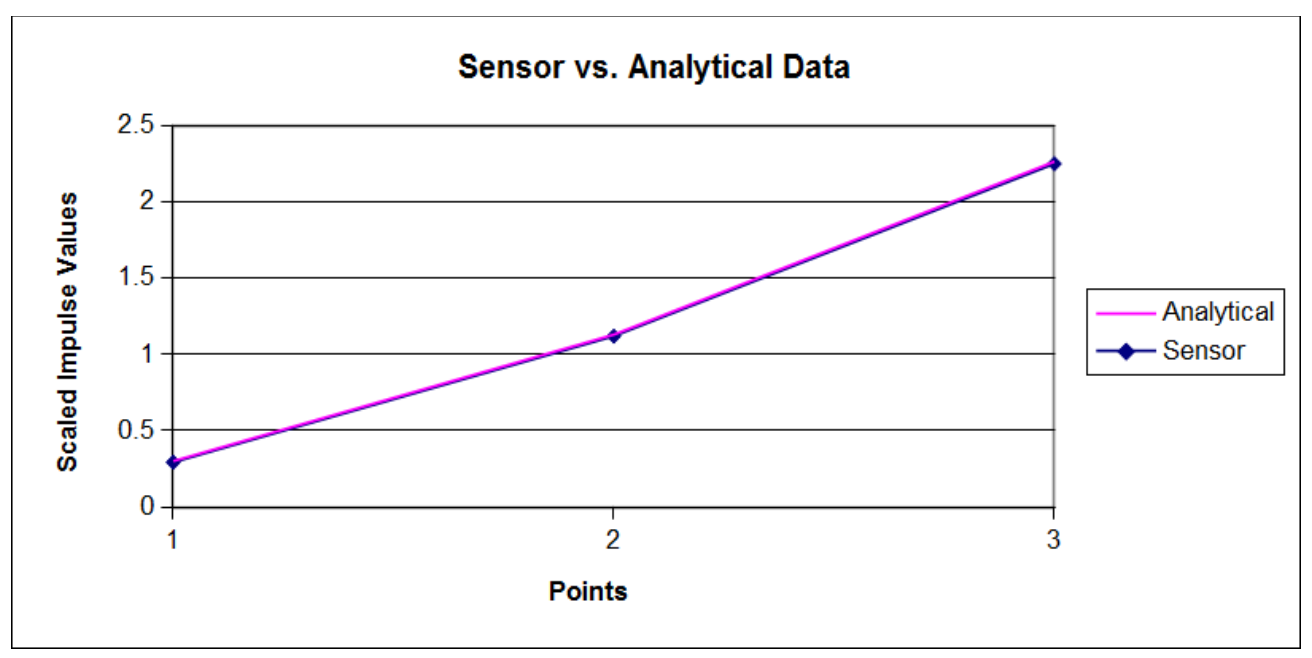

Figure 15: Sensor Impulse Values vs. Analytical Impulse Values

After the data were collected, the points were analyzed to determine the peaks of the five different laser pulses per sample. The force values for each sample were averaged for each pulse, as show in Table 4. The .005" thick sample had a flatter thrust response curve over the five pulses for each sample compared to the $.010 "$ thick sample, which had a higher peak but dropped to much lower thrust values after the thrust peak. The overall thrust of the $.020 "$ thick sample started with low thrust and peaked to a lesser thrust, dropping nearly as low as the $.010 "$ thick samples.

The uncertainty of the values was calculated using standard statistical methods. The standard deviation, $\sigma_{\mathrm{m}}$, for the population was calculated with the following formula:

$$
\sigma_{m}=\sqrt{\frac{\sum_{i=1}^{N}\left(x_{i}-\bar{x}\right)^{2}}{N(N-1)}}
$$


Using $\sigma_{\mathrm{m}}$ along with the population size the uncertainty, $\epsilon$, was found using the following equation, where, $\mathrm{x}$, represents the quantity of interest:

$$
\epsilon_{x}=\frac{\sigma_{x}}{x}
$$

Table 4. Average Force Per Consecutive Pulse for Sample Thicknesses . $005^{\prime \prime} .010^{\prime \prime}$ and .02

\begin{tabular}{|c|c|c|}
\hline .005 Ave. Force $(\mu \mathrm{N})$ & .010 Ave. Force $(\mu \mathrm{N})$ & .020 Ave. Force $(\mu \mathrm{N})$ \\
\hline $1012 \pm 36 \%$ & $863 \pm 33 \%$ & $600 \pm 27 \%$ \\
\hline $1142 \pm 20 \%$ & $1353 \pm 33 \%$ & $913 \pm 34 \%$ \\
\hline $962 \pm 26 \%$ & $1373 \pm 30 \%$ & $1041 \pm 26 \%$ \\
\hline $864 \pm 25 \%$ & $932 \pm 41 \%$ & $731 \pm 35 \%$ \\
\hline $902 \pm 26 \%$ & $634 \pm 32 \%$ & $680 \pm 38 \%$ \\
\hline
\end{tabular}

The first pulse is of primary importance as the mechanism being used in the proposed thrusters as a fuel delivery system was a thin polymer tape. Comparing the first pulse thrust values, the $.005^{\prime \prime}$ thick sample had the most thrust, followed by the $.010 "$ and then, finally, the $.020 "$ sample. This is advantageous, as it only took the laser 5 pulses to completely ablate through the $.005 "$ sample as it could be seen with the naked eye. Comparatively, for the $.020 "$ sample, after the first pulses, the thrust output dropped below the measurable level and, after receiving over 20 pulses, the depth of the hole of the ablated material had not progressed beyond the depth after the first 10 pulses. The thrust values were promising, as the trend showed that the thinner samples have a higher thrust for the first pulse than the thicker samples.

The Cm values of the samples followed the same curves (Figure 16) as the force values calculated, but this was an indicator of the amount of the energy input into the 
system that was being converted into thrust. The $\mathrm{Cm}$ values were lower than desired but this was because of the longer pulse length used to get a measurable result. Previous results from other experiments using specialized polymers (e.g., Urech et al., 2007) have measured $\mathrm{Cm}$ values at orders of magnitude greater than that measured for the POM.

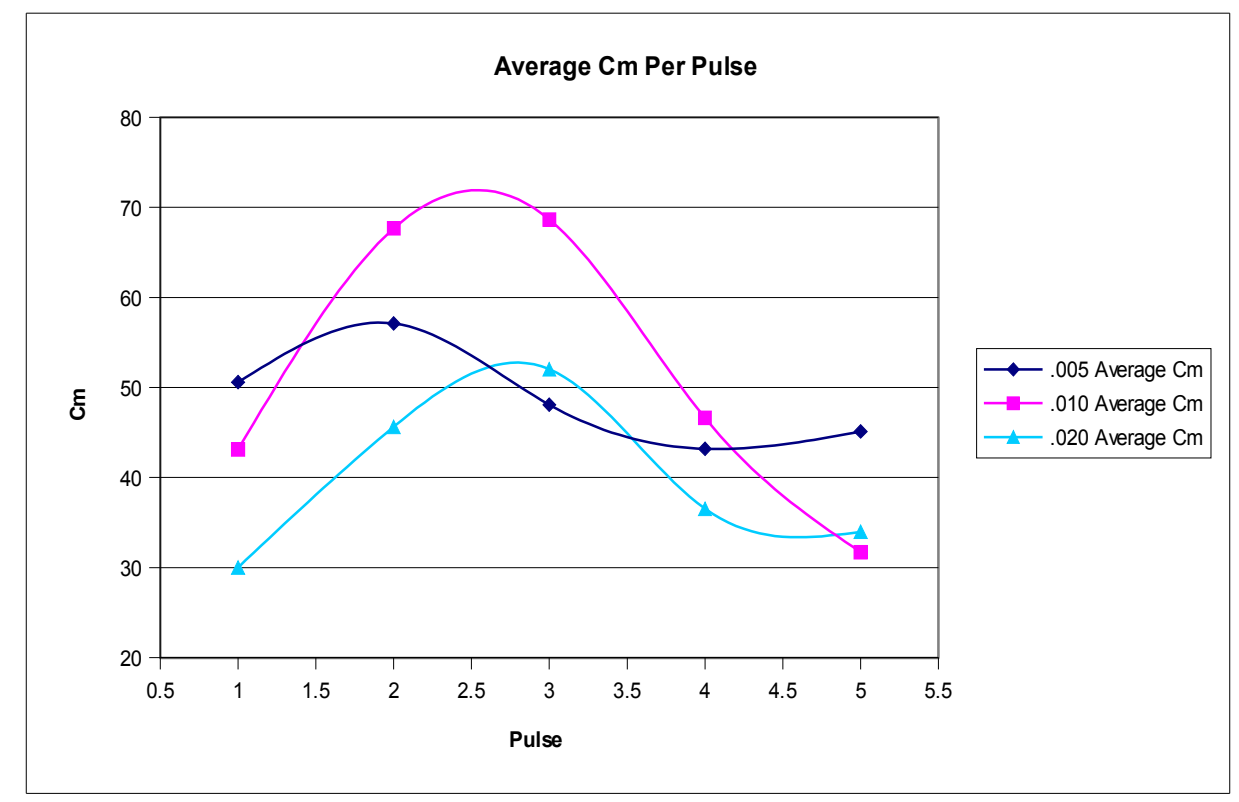

Figure 16. Average Cm Per Consecutive Pulse

\section{Shadowgraph Data}

The shadowgraph was utilized to capture the exhaust velocity of the plume from the laser pulse. The plume was recorded at $1200 \mathrm{fps}$ and then analyzed using a video processing software, which then using the frame rate of the video, the number of frames was counted between the laser pulse and the predetermined travel distance of $10 \mathrm{~mm}$ to calculate the plume's velocity. In Figure 17 (below), the exhaust plume is the darker 
circle propagating from the right of the target platform and has just reached the measurement scale marker of $10 \mathrm{~mm}$.

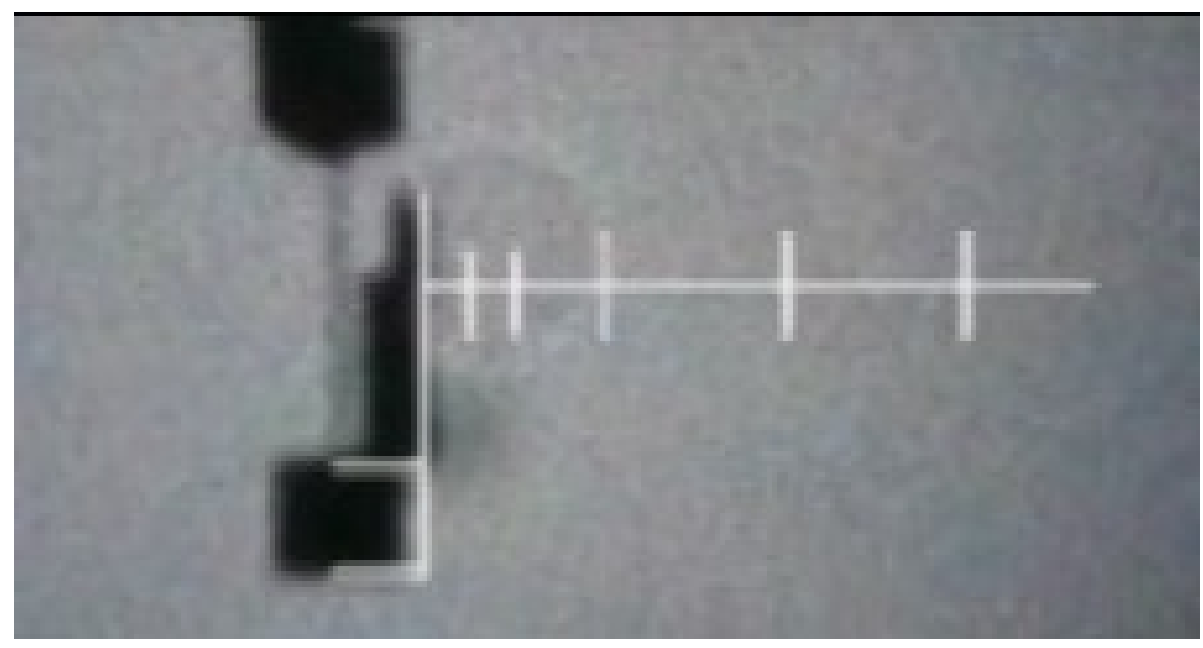

Figure 17 Shadowgraph Shock wave of a .005" thick POM sample

The exhaust velocity was greatest for the $.005 "$ POM with the $.010 "$ and $.020 "$ POM samples following respectively (Figure 18), though the initial pulse velocity was greater for the $.010 "$ POM samples - they reduce to less than the .005" samples by the second pulse yet they still retain a greater velocity than the $.020 "$ samples. This velocity difference between the $.005 ", .010 "$, and $.020 "$ samples correlated with the force data measured by the load cell, showing that the $.005 "$ was better at providing thrust than the other two samples and that, even though the .005 " sample was ablated completely through by the fifth pulse, the $.010 "$ and $.020 "$ sample's thrust and exhaust velocity provided no additional advantage beyond that pulse count; in fact, they resulted in less thrust and exhaust velocity than the $.005 "$ samples before the 5 th pulse was reached. 


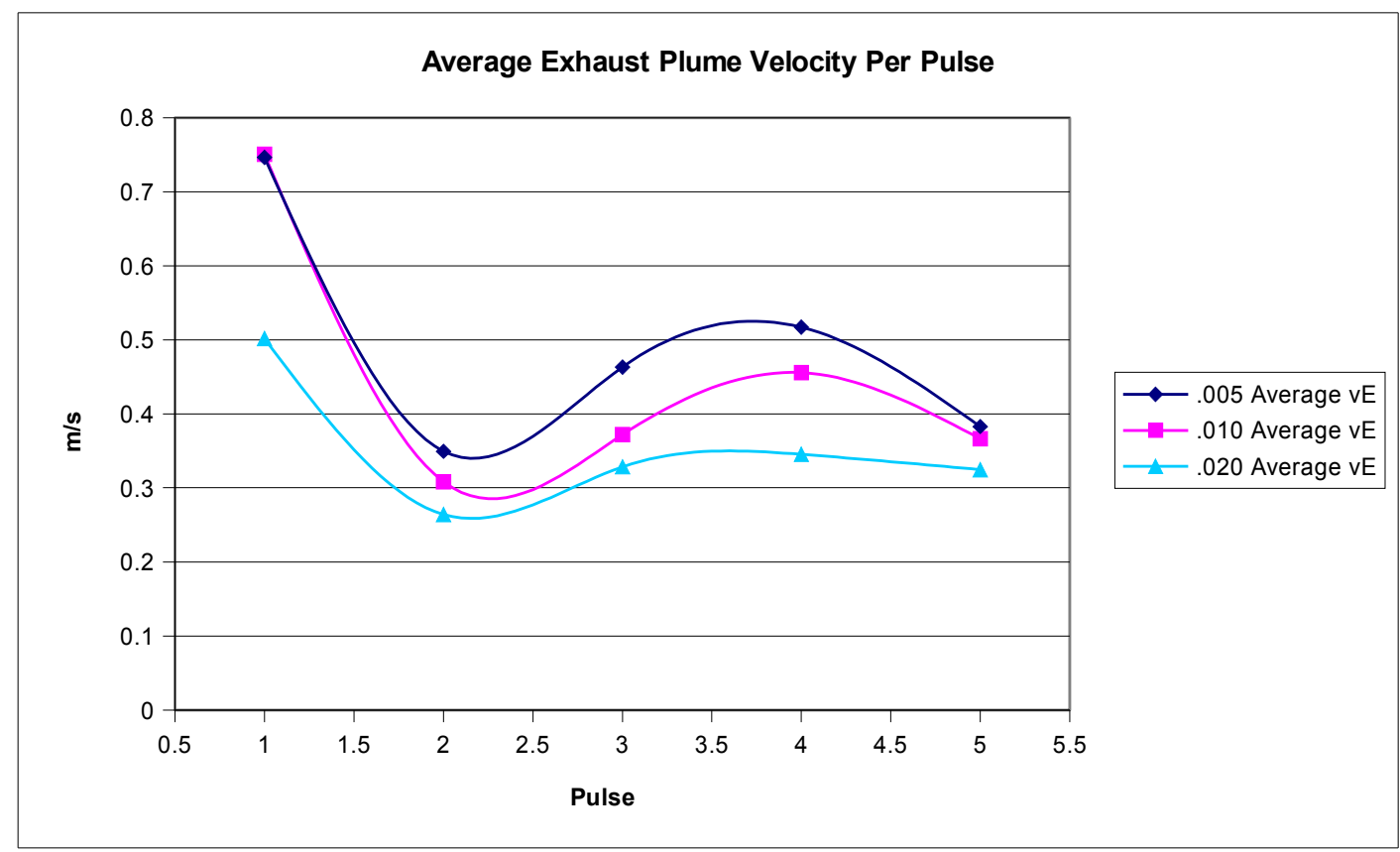

Figure 18. Exhaust Velocity for POM Samples of Thickness .005", .010" and .020"

The exhaust velocity was very slow and, as such, the resulting Isp values were reflected in the results, as shown in Table 5. The reasons for the low exhaust velocity were a combination of the image quality of the shadowgraph and the sensitivity of the camera capturing the shockwave. If the sensitivity of the data collection system was increased and, with the addition of a piezoelectric sensor, configured to detect light, the Isp could then correctly be analyzed. It also appears that there is a two stage combustion occurring in all three of the samples thicknesses, as show in Figure 19, Figure 20, and Figure 21. It can be seen that there was an initial slow moving burn phase when the laser first hit the surface and that, as the particles then ejected from the surface, the laser ignited the particles, creating a secondary combustion and producing a very fast-moving shock. Another factor was the amount of energy required to initiate the ablation event. 
The POM needed a surface dopant to initiate the ablation, after which point the POM was conditioned at the molecular level to a point at which it would absorb energy from the laser for the consecutive pulses.

Table 5. Isp for POM of Thickness .005", .010" and .020"

\begin{tabular}{|l|l|l|l|}
\hline Pulse & .005 Average Isp & .010 Average Isp & .020 Average Isp \\
\hline 1 & 0.07607 & 0.0765 & 0.05113 \\
2 & 0.03560 & 0.0314 & 0.02691 \\
3 & 0.04722 & 0.0379 & 0.03347 \\
4 & 0.05271 & 0.0464 & 0.03518 \\
5 & 0.03902 & 0.0373 & 0.03308 \\
\hline
\end{tabular}

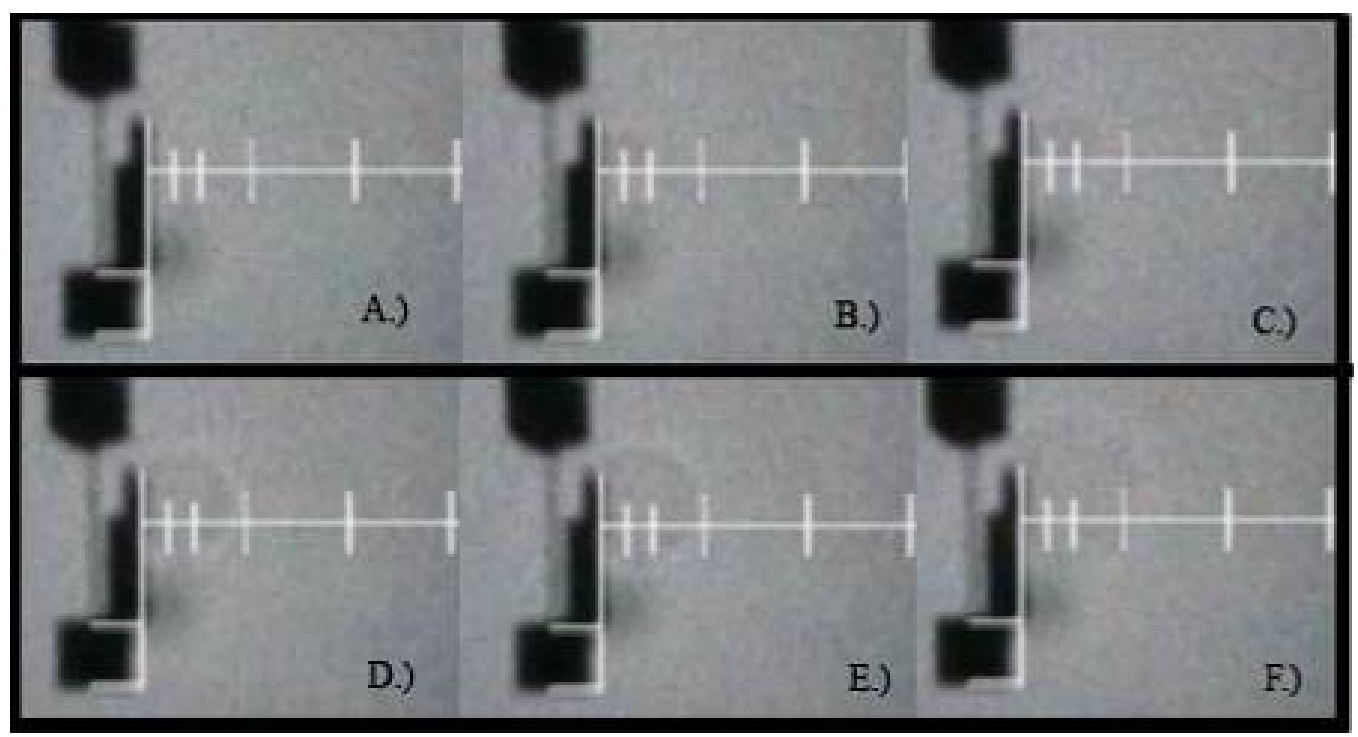

Figure 19. Progression of .005" sample Shockwave. A.) Pre-pulse, B.) Initial burn, C.) formation of initial bubble, D, E and F further expansion of shock 


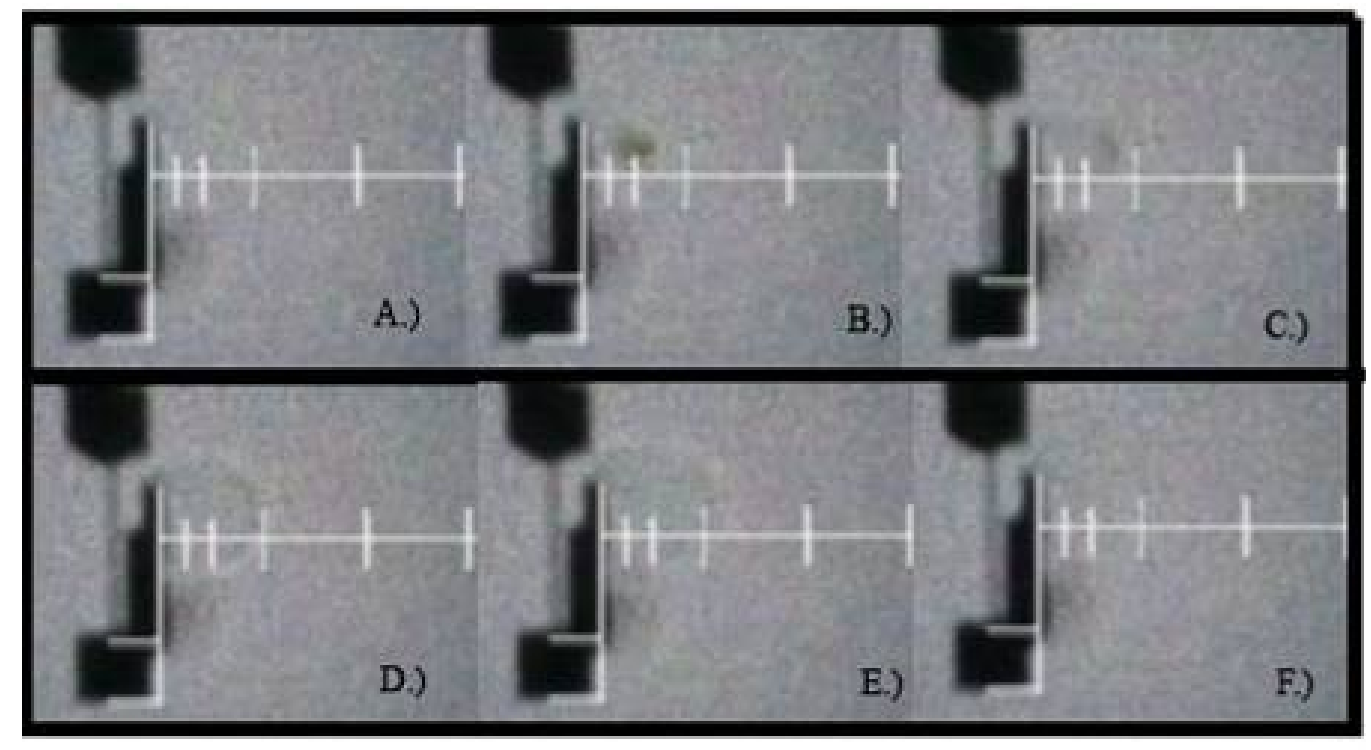

Figure 20. Progression of .010" sample Shockwave. A.) Pre-pulse, B.) Initial burn, C.) formation of initial bubble, D, E and F further expansion of shock

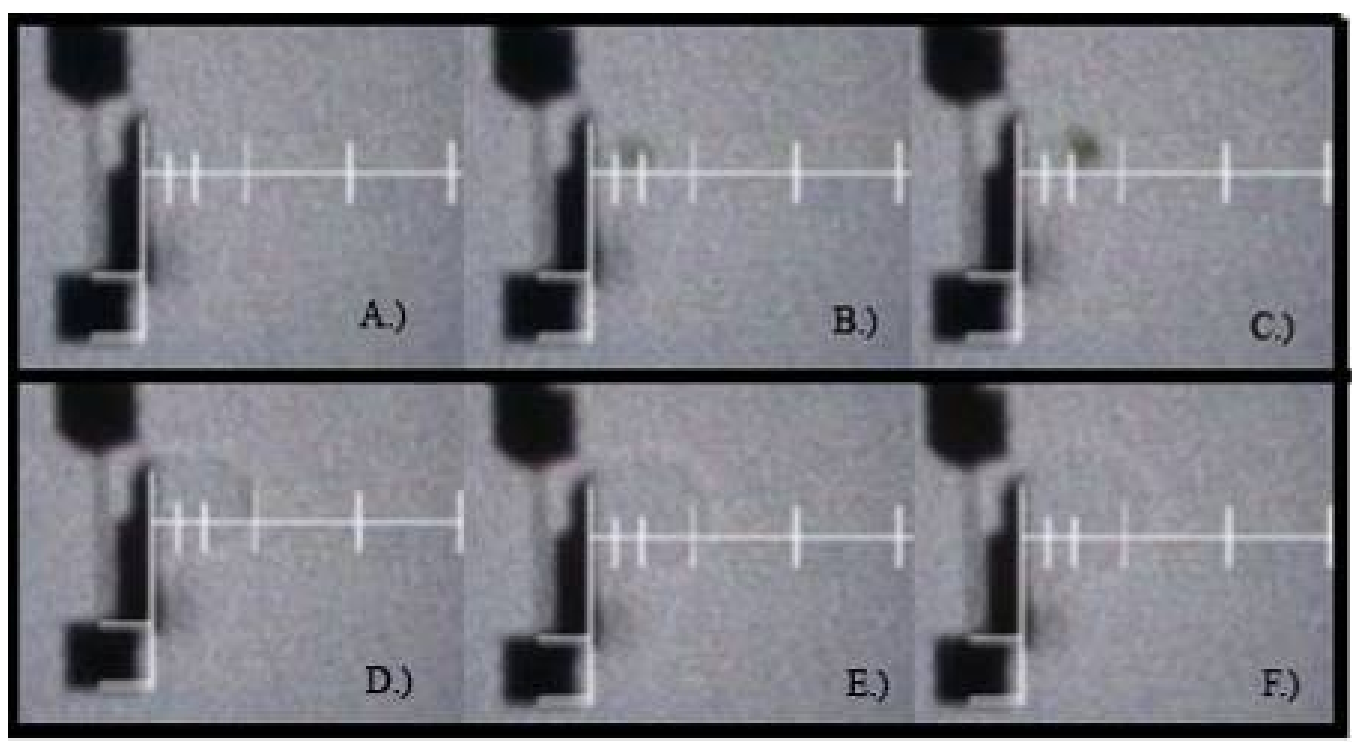

Figure 21. Progression of .020" sample Shockwave. A.) Pre-pulse, B.) Initial burn, C.) further burning, D,

E and $\mathrm{F}$ expansion of shock 
The ablation efficiency $\left(\eta_{\mathrm{AB}}\right)$ parameter takes the $\mathrm{Cm}$, which is the amount of thrust per Watt, and multiplies it by the exhaust velocity. The ablation efficiency parameter can be determined, as shown in Table 6 , after measuring the exhaust velocity with the shadowgraph. The desired value range is $75 \%$ or greater.

Table 6. Ablation Efficiency Parameter for .005", .010" and .020" Thick Samples

\begin{tabular}{|lll|}
\hline$\eta_{\mathrm{AB}} .005$ & $\mathrm{Cm}$ & $\mathrm{v}_{\mathrm{e}}$ \\
$17 \%$ & 51 & 0.7463 \\
\hline$\eta_{\mathrm{AB}} .010$ & $\mathrm{Cm}$ & $\mathrm{v}_{\mathrm{e}}$ \\
$17 \%$ & 43 & 0.7508 \\
\hline$\eta_{\mathrm{AB}} .020$ & $\mathrm{Cm}$ & $\mathrm{v}_{\mathrm{e}}$ \\
$7 \%$ & 30 & 0.5016 \\
\hline
\end{tabular}

\section{Discussion}

Initially, the POM represents a good candidate as a viable polymer for use as a fuel for a low powered laser ablation thruster. It absorbs energy well at the wavelength of an IR laser when compared to other polymers, has a desirable method of decomposition when heated to the proper temperature, and is easy to manufacture. The thrust values of the three different thicknesses of POM were strong, in the micro-Newton range, and met the basic requirements for a micro-thruster to be used on pico and nano satellites. However, when compared to values of different polymers used in other experiments, the POM was very inefficient, as can be seen in the comparison in Table 7 . The polymers tested in the previous experiments were glycidyl azide polymer (GAP), poly(vinyl chloride) (PVC), and poly(vinyl nitrate) (PVN), where all of the samples, 
including a "+C", have the addition of carbon nanoparticles in the polymer and the addition of an infrared dopant ("+IR").

Table 7. POM vs. Previous Experiments Using Different Polymers

\begin{tabular}{|l|r|r|r|r|}
\hline Urech et. al. 2007 & \multicolumn{1}{|c|}{ GAP+C } & \multicolumn{1}{c|}{ GAP+IR } & PVN+C & PVC+C \\
\hline Cm $(\mu$ N/W) & 865 & 1574 & 310 & 635 \\
\hline Polyoxymethelyne & $.005 "$ POM & $.010 "$ POM & $.020 "$ POM & \\
\hline Cm $(\mu$ N/W $)$ & 51 & 43 & 30 & \\
\hline
\end{tabular}

The essentially undoped POM is more than a factor of 10 lower for the values of Cm compared to the Urech data, all of which had been tailored with dopants to make the polymers either absorb IR energy more efficiently or to increase the mass flow rate for the specific polymers. The primary cause of the low $\mathrm{Cm}$ values can be determined with the equation, $C m=\frac{I(N \cdot s)}{E(W \cdot s)}$. The problem is that the amount of energy from the laser required to generate the resulting impulse is too large. The longer pulse required to achieve a measurable result with the POM reduces the $\mathrm{Cm}$, showing that the plain, undoped POM does not absorb the 980nm light efficiently enough to be used as a polymer fuel for a micro thruster given the parameters laid out in this experiment.

It can be seen that the thickness of the POM samples played a part in how strong an impulse was recorded on the load cell and also affected the exhaust velocity. This corroborates with other studies showing that thinner samples are more efficient at releasing energy. The $.005 "$ sample was ablated in its entirety within five pulses with no visual signs of melting, whereas both the .010" and .020" samples showed signs of 
melting on the edges of the spot where the laser hit; further, continuing to hit the target with the laser produced no measurable results after the $5^{\text {th }}$ pulse. With this information, one can postulate that the thicker amount of material was absorbing the energy from the laser and distributing it to the surrounding material, thus reducing the available energy to create plasma. For future tests, it would be desirable to test films of POM thinner than the .005 " thick samples tested in this experiment and to determine the optimum thickness of POM required to create the maximum amount of thrust, while keeping in mind the tape drive delivery system proposed earlier in this paper.

Initial tests using POM yielded no results, but the addition of a dark surface dopant for the first pulse yielded greater results, as indicated in the exhaust velocity values in Figure 18. For all three sample thicknesses, the first pulse, which had the surface dopant applied, yielded an exhaust velocity greater than all the preceding pulses on the same sample. The fact that POM continued to absorb IR light after the first pulse had removed the dopant, resulting in a measurable impulse, indicates that the manner in which POM breaks down, often described as unzipping (Sinkho et. al. 2011), prepares the material at the molecular level to absorb the IR light and continue to produce thrust. This suggests that if the POM were treated with an IR dopant at the molecular level, the absorption factor of the material would be greatly increased for each subsequent pulse as well as the first pulse. By adding the dopant, hypothetically, the pulse length of the laser could be shortened as the energy from the laser would be transferred into the fuel 
material more efficiently, effectively increasing the $\mathrm{Cm}$ of the POM. This would need to be tested in the future.

The two staged combustion shown in Figure 18, Figure 19, and Figure 20 shows that the sample is burning and not creating a plasma event at the first contact of the laser. The burning is not as efficient as it would be with a true ablation, which indicates that the fluence of the laser is not great enough to initiate the plasma. If the material absorbed the energy better, as discussed earlier, the burning stage could be avoided. Since the material is only burning at the first stage of the laser pulse and does not create a shock pulse until after particles have been ejected, at which point the shock pulse occurs, more energy was needed from the laser, in the form of a longer laser pulse, to create the plasma.

Because the experiment was performed only in a partial vacuum, to primarily remove water vapor, the velocity of the exhaust plume was affected. The molecules in the chamber were colliding with the molecules in the exhaust plume. The resultant collisions had a significant braking effect on the velocity of the exhaust. Future work must be conducted in a complete vacuum to be able to properly measure the exhaust velocity to properly be able to calculate the Isp.

In Figure 17, the exhaust plume is expanding in a continuous growing circle. If a nozzle focused the energy in the direction desired, the velocity could be increased. The simple addition of a nozzle and an IR dopant to the POM and running the experiment in a complete vacuum would potentially increase Isp and ablation efficiency enough to make 
POM a viable ablation fuel comparable to the results achieved by other researchers with different polymers.

\section{Conclusion}

With increased interest in military and commercial applications for pico and nano satellites, research into improving the station-keeping capabilities of these small satellites is part of a growing field. PPTs and laser ablation thrusters are two such solutions. It was proposed in this paper that the laser ablation thruster was a reasonable PPT option with the potential to decrease the complexity of the thruster. The focus of this paper was on using a 20 Watt solid-state diode laser at $980 \mathrm{~nm}$ pulsed using TTL modulation, and the fuel of choice was polyoxymethelyne (POM).

The basic design of the micro-thruster as put forth by Urech et al. (2007) is a solid state diode laser firing through an IR transparent tape, such as Kapton, which would then ablate the polymer film deposited on the opposite side of the tape. Utilizing the forward plasma acceleration mechanism, the thrust produced would be generated in the same direction as the laser pulse. The tape with the polymer film would then be advanced to provide fresh material for use as fuel. For this type of design, the critical work to be done is to determine the best polymer for use as a fuel in the micro-thruster.

The polymer POM produced significant amounts of thrust, upwards of $1 \mathrm{mN}$ at the largest peaks, with an uncertainty of $30 \%$, but at the cost of a large laser pulse width. The large pulse width resulted in a low $\mathrm{Cm}$ value compared to other tailored polymers, with the largest first pulse value coming from the $.005 "$ thick sample and the smallest 
value from the $.020 "$ thick sample. Although the magnitudes of the $\mathrm{Cm}$ were not as high as expected because of the wider pulse width, more thrust was produced for the thinner samples and thrust decreased as the samples got thicker, as expected. Even though the polymer had an absorption coefficient of $2 \times 10^{6} \mathrm{~m}^{-1}$ for the $980 \mathrm{~nm}$ wavelength, the addition of a surface dopant to assist the absorption of the IR light to initiate the ablation process was required. The subsequent drop in exhaust velocity as measured following the initial pulse and the brief rise indicate that if the polymer were doped at the molecular level with an IR absorbent, then the efficiency of the POM as an ablation fuel would be increased. The rise in thrust produced after the second pulse also indicates that the polymer breakdown characteristics prepares the POM at the molecular level to absorb the laser more completely since, after the first pulse, all of the surface dopant is removed.

If POM is to be used as a fuel for low power solid-state laser ablation propulsion for pico and nano satellites, further work must be done to improve the efficiency of the polymer's ablation characteristics. First, all subsequent work should be performed in a full vacuum to minimize the braking effect of the molecule collisions in the chamber. The two-stage ablation event where the polymer initially ejected particles and then produced the shock was inefficient, as a result of which the Isp was low. In addition, the system designed to measure the exhaust velocity of the POM was not sensitive enough to properly capture exhaust velocity. Due to this inadequacy, improved optics and video capture rates with the addition of a piezoelectric sensor configured to detect light would be required to determine the resulting plume produced by the ablation event. Further 
research could include adding an IR dopant to the polymer and measuring the performance difference between the doped and un-doped POM. Another potential experiment would be to test the efficiency of the ablation process and discover whether there is an increase in thrust and Isp if a nozzle is added to the POM, which could potentially help to accelerate the exhaust velocity in the direction desired for the thrust generated. Finally, a detailed uncertainty analysis should be conducted as further work is completed.

With increased interest and research into pico and nano satellite constellations, it becomes imperative that a propulsion system be developed to allow for station-keeping maneuvers. A laser ablation micro-thruster could provide a solution. Work has been done showing that polymers that provide the required amount of thrust and Isp can be used as a fuel for laser ablation. POM was tested in this paper and proved to provide the required thrust but to lack sufficient Isp. Further work, however, could show POM to be a viable material as a fuel for a laser based micro-thruster. 


\section{References}

"Boeing to Design DARPA Airborne Satellite Launch Vehicle." To Design DARPA Airborne Satellite Launch Vehicle. Boeing, 14 Mar. 2014. Web. 17 Apr. 2015.

Bohn, W. L. (2008). Laser propulsion - Quo vadis. Beamed Energy Propulsion: Fifth International Symposium on Beamed Energy Propulsion, 997, 47-55. Retrieved from http://dx.doi.org/10.1063/1.2931919

Brazolin, H., Rodrigues, N. A., \& Minucci, M. A. (2008). Thrust measurements in ballistic Pendulum ablative laser propulsion experiments. Beamed Energy Propulsion: Fifth International Symposium on Beamed Energy Propulsion, 997, 143-146.

Cook, J. R. (2008). Laser propulsion - Is it another myth or a real potential. Beamed Energy Propulsion: Fifth International Symposium on Beamed Energy Propulsion, 997, 109-118.

"DARPA Developing Operational Pathfinder for ALASA Air Launch System SpaceNews.com." SpaceNews.com. N.p., 02 June 2014. Web. 17 Apr. 2015.

Gualini, M.M, Khan, S.A., Zulfiqar, K. (2006), Development of laser propelled "semiperpetual" rotary machine. Beamed Energy Propulsion: Fourth International Symposium on Beamed Energy Propulsion, 830, pp. 591-599.

Horisawa, H., \& Kimura, I. (2002). Fundamental study on laser plasma accelerator for propulsion applications. Vacuum, 65, 389-396.

Horisawa, H., Sumida, S., Yonamine, H., \& Funaki, I. (2013). Thrust generation through low-power laser metal interaction for space propulsion applications. Vacuum, 88, 75-78.

Rinaldi, C. A., Boggio, N. G., Rodriguez, D., Lamagna, A., Boselli, A., Manzano, F., Codnia, J., \& Azcarate, M. L. (2011). Dependence of Cm on the composition of solid binary propellants in ablative laser propulsion. Applied Surface Science, 257, 2019-2023.

Sinkho, J. E., \& Sasoh, A. (2011). Review of CO 2 laser ablation propulsion with polyoxythylene. International Journal of Aerospace Innovations, 3(2), 93-129.

Urech, L., Lippert, T., Phipps, C. R., \& Wokaun, A. (2007). Polymers as fuel for laserbased microthrusters: An investigation of thrust, material, plasma and shockwave properties. Applied Surface Science, 253, 7646-7650. 
Urech, L., Lippert, T., Phipps, C. R., \& Wokaun, A. (2007). Polymer ablation: From fundamentals of polymer design to laser plasma thruster. Applied Surface Science, 253, 6409-6415

USASMDC. (2014). Soldier-Warfighter Operationally Responsive Deployer for Space, (SMDC 0812/0250), Huntsville AL. Retrieved from http://www.smdc.army.mil/FactSheets/archive/SWORDS.pdf. 


\section{Appendix A. Glossary}

$\alpha$-Absorption coefficent

$\beta$ - Damped constant

$\mathrm{Cm}$ - Coupling Coefficient

E - Laser energy

$\varepsilon_{\mathrm{x}}$ - Uncertainty

$\mathrm{F}$ - Thruster

fps - Frames per second

g - Gravitational constant

GAP - glycidyl azide polymer

I - Impulse

Isp - Specific impulses

$\mathrm{k}$ - Imaginary refractive index

$\lambda$ - Wavelength

$\mathrm{m}$ - Mass ejected

$\mathrm{n}$ - Real refractive index

$\eta_{\mathrm{AB}}-$ Ablation efficiency parameter

$\Omega$ - Angular frequency

$\mathrm{P}$ - Power imparte to the system

POM - Polyoxymethelyne

PPT - Pulsed Plasma Thruster

PTFE - Polytetrafluoroethylene

PVC - Poly(vinyl chloride)

PVN - Poly(vinyl nitrate)

$\sigma_{\mathrm{m}}-$ Mean value standard deviation

TTL - Transistor Transistor Logic

$\omega_{0}$ - Un-damped angular frequency

$\Delta \mathrm{v}$ - Average velocity of the mass

$\mathrm{V}_{\mathrm{e}}-$ Exhaust velocity 


\section{Appendix B. Processed Results From Raw Data for the .005" Thick Samples}

$.005 "$ Thick Sample Results

\begin{tabular}{|c|c|c|c|c|c|c|c|c|c|c|c|}
\hline Impulse & Sample 1 & Sample 2 & Sample 3 & Sample 4 & Sample 5 & Sample 6 & Sample 7 & Sample 8 & Sample 9 & Sample 10 & AVE \\
\hline 1 & 0.0073 & 0.0089 & 0.0067 & 0.0055 & 0.0055 & 0.0095 & 0.0093 & 0.0179 & 0.0095 & 0.0067 & 0.00868 \\
\hline 2 & 0.0094 & 0.0089 & 0.0067 & 0.0067 & 0.0095 & 0.0134 & 0.0111 & 0.0112 & 0.0116 & 0.0095 & 0.0098 \\
\hline 3 & 0.0073 & 0.0089 & 0.0039 & 0.0055 & 0.0095 & 0.0116 & 0.0093 & 0.0112 & 0.0067 & 0.0086 & 0.00825 \\
\hline 4 & 0.0073 & 0.0077 & 0.0067 & 0.0055 & 0.0086 & 0.0095 & 0.0044 & 0.0112 & 0.0077 & 0.0055 & 0.00741 \\
\hline 5 & 0.0073 & 0.0077 & 0.0067 & 0.0055 & 0.0086 & 0.0116 & 0.0044 & 0.0112 & 0.0077 & 0.0067 & 0.00774 \\
\hline AVE & 0.00772 & 0.00842 & 0.00614 & 0.00574 & 0.00834 & 0.01112 & 0.0077 & 0.01254 & 0.00864 & 0.0074 & \\
\hline Plumes & Sample 1 & Sample 2 & Sample 3 & Sample 4 & Sample 5 & Sample 6 & Sample 7 & Sample 8 & Sample 9 & Sample 10 & AVE \\
\hline 1 & 0.5 & 0.343 & 0.572 & 1.2 & 1.2 & 1.2 & 0.414 & 0.414 & 0.286 & 1.334 & 0.7463 \\
\hline 2 & 0.8 & 0.343 & 0.572 & 0.231 & 0.343 & 0.375 & 0.177 & 0.214 & 0.261 & 0.177 & 0.3493 \\
\hline 3 & 0.857 & 0.706 & 0.706 & 0.387 & 0.273 & 0.109 & 0.462 & 0.171 & 0.462 & 0.5 & 0.4633 \\
\hline 4 & 0.706 & 0.445 & 0.429 & 0.8 & 0.308 & 0.5 & 1 & 0.156 & 0.6 & 0.227 & 0.5171 \\
\hline 5 & 0.522 & 0.4 & 0.286 & 0.261 & 0.522 & 0.191 & 1.091 & 0.286 & 0.164 & 0.105 & 0.3828 \\
\hline AVE & 0.677 & 0.4474 & 0.513 & 0.5758 & 0.5292 & 0.475 & 0.6288 & 0.2482 & 0.3546 & 0.4686 & \\
\hline $\begin{array}{l}\text { Spot Size } \\
\text { (m) }\end{array}$ & 0.0015 & $\begin{array}{l}\text { Laser } \\
\text { Watt }\end{array}$ & 20 & $\begin{array}{l}\text { Pulse } \\
\text { Length } \\
\text { (sec) }\end{array}$ & 0.05 & $\begin{array}{l}\text { Laser } \\
\text { Energy } \\
\text { Imparted } \\
\text { (Joules) }\end{array}$ & 1 & $\mathrm{~g}\left(\mathrm{~m} / \mathrm{s}^{\wedge} 2\right)$ & 9.81 & $\begin{array}{l}\text { Scaling } \\
\text { factor for } \\
\text { sensor }\end{array}$ & 0.007013 \\
\hline $\mathrm{Cm}(\mathrm{N} / \mathrm{W})$ & Sample 1 & Sample 2 & Sample 3 & Sample 4 & Sample 5 & Sample 6 & Sample 7 & Sample 8 & Sample 9 & Sample 10 & AVE \\
\hline 1 & $5.11949 \mathrm{E}-05$ & $6.24 \mathrm{E}-05$ & 4.7E-05 & $3.86 \mathrm{E}-05$ & $3.86 \mathrm{E}-05$ & $6.66 \mathrm{E}-05$ & $6.52 \mathrm{E}-05$ & 0.000126 & $6.66 \mathrm{E}-05$ & 4.7E-05 & $6.09 \mathrm{E}-05$ \\
\hline 2 & $6.59222 \mathrm{E}-05$ & $6.24 \mathrm{E}-05$ & 4.7E-05 & 4.7E-05 & $6.66 \mathrm{E}-05$ & $9.4 \mathrm{E}-05$ & $7.78 \mathrm{E}-05$ & $7.85 \mathrm{E}-05$ & $8.14 \mathrm{E}-05$ & $6.66 \mathrm{E}-05$ & $6.87 \mathrm{E}-05$ \\
\hline 3 & $5.11949 \mathrm{E}-05$ & $6.24 \mathrm{E}-05$ & $2.74 \mathrm{E}-05$ & $3.86 \mathrm{E}-05$ & $6.66 \mathrm{E}-05$ & $8.14 \mathrm{E}-05$ & $6.52 \mathrm{E}-05$ & $7.85 \mathrm{E}-05$ & $4.7 \mathrm{E}-05$ & $6.03 \mathrm{E}-05$ & $5.79 \mathrm{E}-05$ \\
\hline 4 & $5.11949 \mathrm{E}-05$ & $5.4 \mathrm{E}-05$ & 4.7E-05 & $3.86 \mathrm{E}-05$ & $6.03 \mathrm{E}-05$ & $6.66 \mathrm{E}-05$ & $3.09 \mathrm{E}-05$ & $7.85 \mathrm{E}-05$ & $5.4 \mathrm{E}-05$ & $3.86 \mathrm{E}-05$ & $5.2 \mathrm{E}-05$ \\
\hline 5 & $5.11949 \mathrm{E}-05$ & $5.4 \mathrm{E}-05$ & 4.7E-05 & $3.86 \mathrm{E}-05$ & $6.03 \mathrm{E}-05$ & $8.14 \mathrm{E}-05$ & $3.09 \mathrm{E}-05$ & $7.85 \mathrm{E}-05$ & $5.4 \mathrm{E}-05$ & 4.7E-05 & $5.43 \mathrm{E}-05$ \\
\hline$s p$ & Sample 1 & Sample 2 & Sample 3 & Sample 4 & Sample 5 & Sample 6 & Sample 7 & Sample 8 & Sample 9 & Sample 10 & AVE \\
\hline
\end{tabular}




$\begin{array}{lllllllllll}0.0509684 & 0.034964 & 0.058308 & 0.122324 & 0.122324 & 0.122324 & 0.042202 & 0.042202 & 0.029154 & 0.135984 & 0.076075 \\ 0.081549439 & 0.034964 & 0.058308 & 0.023547 & 0.034964 & 0.038226 & 0.018043 & 0.021814 & 0.026606 & 0.018043 & 0.035607 \\ 0.087359837 & 0.071967 & 0.071967 & 0.03945 & 0.027829 & 0.011111 & 0.047095 & 0.017431 & 0.047095 & 0.050968 & 0.047227 \\ 0.07196738 & 0.045362 & 0.043731 & 0.081549 & 0.031397 & 0.050968 & 0.101937 & 0.015902 & 0.061162 & 0.02314 & 0.052712 \\ 0.053211009 & 0.040775 & 0.029154 & 0.026606 & 0.053211 & 0.01947 & 0.111213 & 0.029154 & 0.016718 & 0.010703 & 0.039021\end{array}$

\section{Appendix C. Processed Results From Raw Data for the .010" Thick Samples}

010" Samples

\begin{tabular}{|c|c|c|c|c|c|c|c|c|c|c|c|}
\hline Impulse & Sample 1 & Sample 2 & Sample 3 & Sample 4 & Sample 5 & Sample 6 & Sample 7 & Sample 8 & Sample 9 & Sample 10 & AVE \\
\hline 1 & 0.0075 & 0.0134 & 0.0067 & 0.0045 & 0.0045 & 0.0053 & 0.0063 & 0.0099 & 0.0067 & 0.0092 & 0.0074 \\
\hline 2 & 0.0075 & 0.0134 & 0.0156 & 0.0089 & 0.0119 & 0.0089 & 0.0083 & 0.0143 & 0.0067 & 0.0206 & 0.01161 \\
\hline 3 & 0.012 & 0.0045 & 0.0067 & 0.0112 & 0.0158 & 0.0134 & 0.0125 & 0.0166 & 0.0159 & 0.0092 & 0.01178 \\
\hline 4 & 0.0075 & 0.0022 & 0.0045 & 0.0045 & 0.0112 & 0.0156 & 0.0099 & 0.0099 & 0.0081 & 0.0066 & 0.008 \\
\hline 5 & 0.0075 & 0.0045 & 0.0045 & 0.0023 & 0.0045 & 0.0067 & 0.0064 & 0.0083 & 0.0067 & 0.003 & 0.00544 \\
\hline AVE & 0.0084 & 0.0076 & 0.0076 & 0.00628 & 0.00958 & 0.00998 & 0.00868 & 0.0118 & 0.00882 & 0.00972 & \\
\hline Plumes & Sample 1 & Sample 2 & Sample 3 & Sample 4 & Sample 5 & Sample 6 & Sample 7 & Sample 8 & Sample 9 & Sample 10 & AVE \\
\hline 1 & 0.8 & 1.2 & 0.923 & 0.445 & 0.429 & 1.501 & 0.353 & 0.522 & 1 & 0.335 & 0.7508 \\
\hline 2 & 0.353 & 0.279 & 0.316 & 0.3 & 0.231 & 0.414 & 0.235 & 0.308 & 0.293 & 0.353 & 0.3082 \\
\hline 3 & 0.353 & 0.343 & 0.255 & 0.462 & 0.333 & 0.375 & 0.353 & 0.3 & 0.445 & 0.5 & 0.3719 \\
\hline 4 & 0.522 & 0.261 & 0.375 & 0.623 & 0.273 & 0.8 & 0.293 & 0.364 & 0.5 & 0.546 & 0.4557 \\
\hline 5 & 0.3 & 0.25 & 0.462 & 0.429 & 0.333 & 0.632 & 0.316 & 0.293 & 0.375 & 0.273 & 0.3663 \\
\hline AVE & 0.4656 & 0.4666 & 0.4662 & 0.4518 & 0.3198 & 0.7444 & 0.31 & 0.3574 & 0.5226 & 0.4014 & \\
\hline $\begin{array}{l}\text { Spot } \\
\text { Size } \\
(\mathrm{mm})\end{array}$ & 1.15 & $\begin{array}{l}\text { Laser } \\
\text { Watt }\end{array}$ & 20 & $\begin{array}{l}\text { Pulse } \\
\text { Length } \\
\text { (sec) }\end{array}$ & 0.05 & $\begin{array}{l}\text { Laser } \\
\text { Energy } \\
\text { Imparted } \\
\text { (Joules) }\end{array}$ & 1 & $\mathrm{~g}\left(\mathrm{~m} / \mathrm{s}^{\wedge} 2\right)$ & 9.81 & $\begin{array}{l}\text { Scaling } \\
\text { factor for } \\
\text { sensor }\end{array}$ & 0.007013 \\
\hline $\mathrm{Cm}$ & Sample 1 & Sample 2 & Sample 3 & Sample 4 & Sample 5 & Sample 6 & Sample 7 & Sample 8 & Sample 9 & Sample 10 & AVE \\
\hline 1 & $5.25975 \mathrm{E}-05$ & $9.4 \mathrm{E}-05$ & 4.7E-05 & $3.16 \mathrm{E}-05$ & $3.16 \mathrm{E}-05$ & $3.72 \mathrm{E}-05$ & $4.42 \mathrm{E}-05$ & $6.94 \mathrm{E}-05$ & 4.7E-05 & $6.45 \mathrm{E}-05$ & $5.19 \mathrm{E}-05$ \\
\hline
\end{tabular}




$\begin{array}{lllllllllllll}2 & 5.25975 \mathrm{E}-05 & 9.4 \mathrm{E}-05 & 0.000109 & 6.24 \mathrm{E}-05 & 8.35 \mathrm{E}-05 & 6.24 \mathrm{E}-05 & 5.82 \mathrm{E}-05 & 0.0001 & 4.7 \mathrm{E}-05 & 0.000144 & 8.14 \mathrm{E}-05 \\ 3 & 0.000084156 & 3.16 \mathrm{E}-05 & 4.7 \mathrm{E}-05 & 7.85 \mathrm{E}-05 & 0.000111 & 9.4 \mathrm{E}-05 & 8.77 \mathrm{E}-05 & 0.000116 & 0.000112 & 6.45 \mathrm{E}-05 & 8.26 \mathrm{E}-05 \\ 4 & 5.25975 \mathrm{E}-05 & 1.54 \mathrm{E}-05 & 3.16 \mathrm{E}-05 & 3.16 \mathrm{E}-05 & 7.85 \mathrm{E}-05 & 0.000109 & 6.94 \mathrm{E}-05 & 6.94 \mathrm{E}-05 & 5.68 \mathrm{E}-05 & 4.63 \mathrm{E}-05 & 5.61 \mathrm{E}-05 \\ 5 & 5.25975 \mathrm{E}-05 & 3.16 \mathrm{E}-05 & 3.16 \mathrm{E}-05 & 1.61 \mathrm{E}-05 & 3.16 \mathrm{E}-05 & 4.7 \mathrm{E}-05 & 4.49 \mathrm{E}-05 & 5.82 \mathrm{E}-05 & 4.7 \mathrm{E}-05 & 2.1 \mathrm{E}-05 & 3.82 \mathrm{E}-05 \\ & & & & & & & & & & & & \\ & & & & & & & & & & & & \\ \text { Isp } & \text { Sample 1 } & \text { Sample 2 } & \text { Sample 3 } & \text { Sample 4 } & \text { Sample 5 } & \text { Sample 6 } & \text { Sample 7 } & \text { Sample 8 } & \text { Sample 9 } & \text { Sample 10 } & \text { AVE } \\ 1 & 0.081549439 & 0.122324 & 0.094088 & 0.045362 & 0.043731 & 0.153007 & 0.035984 & 0.053211 & 0.101937 & 0.034149 & 0.076534 \\ 2 & 0.03598369 & 0.02844 & 0.032212 & 0.030581 & 0.023547 & 0.042202 & 0.023955 & 0.031397 & 0.029867 & 0.035984 & 0.031417 \\ 3 & 0.03598369 & 0.034964 & 0.025994 & 0.047095 & 0.033945 & 0.038226 & 0.035984 & 0.030581 & 0.045362 & 0.050968 & 0.03791 \\ 4 & 0.053211009 & 0.026606 & 0.038226 & 0.063507 & 0.027829 & 0.081549 & 0.029867 & 0.037105 & 0.050968 & 0.055657 & 0.046453 \\ 5 & 0.03058104 & 0.025484 & 0.047095 & 0.043731 & 0.033945 & 0.064424 & 0.032212 & 0.029867 & 0.038226 & 0.027829 & 0.037339\end{array}$

\section{Appendix D. Processed Results From Raw Data for the .020" Thick Samples}

$.020 "$ Sample Results

$\begin{array}{ll}\text { Peaks } & \text { Sample 1 } \\ 1 & 0.0045 \\ 2 & 0.0045 \\ 3 & 0.0067 \\ 4 & 0.0045 \\ 5 & 0.0045 \\ \text { AVE } & 0.00494 \\ & \\ \text { Plume } & \text { Sample 1 } \\ 1 & 0.667 \\ 2 & 0.3 \\ 3 & 0.25 \\ 4 & 0.316 \\ 5 & 0.429 \\ \text { AVE } & 0.3924\end{array}$

$\begin{array}{lll}\text { Sample 2 } & \text { Sample 3 } & \text { Sample 4 } \\ 0.0023 & 0.0044 & 0.0044 \\ 0.0046 & 0.0112 & 0.0088 \\ 0.009 & 0.0111 & 0.0088 \\ 0.0046 & 0.0111 & 0.0044 \\ 0.0046 & 0.0111 & 0.0066 \\ 0.00502 & 0.00978 & 0.0066 \\ & & \\ \text { Sample 2 } & \text { Sample 3 } & \text { Sample 4 } \\ 0.75 & 0.632 & 0.316 \\ 0.293 & 0.227 & 0.218 \\ 0.429 & 0.177 & 0.293 \\ 0.4 & 0.185 & 0.324 \\ 0.522 & 0.197 & 0.48 \\ 0.4788 & 0.2836 & 0.3262 \\ & & \\ & & \\ \text { Laser } & & \text { Pulse } \\ \text { Watt } & 20 & \text { (sec) }\end{array}$

\section{Sample 5 \\ Sample 6} 0.0044 0.0044

0.0111

0.0044

0.0044

0.00574

Sample 5

0.316

0.24

0.387

0.462

0.445

0.37

Length 0.0067

0.0134

0.0134

0.0045

0.0045

0.0085

Sample 6

0.324

0.24

0.387

0.286

0.308

0.309

Laser

Energy

Imparted $\begin{array}{ll}\text { Size } & \\ (\mathrm{mm}) & 1.15\end{array}$
Watt
0.05

\section{Sample $7 \quad$ Sample 8 0.0045}

0.0067

0.0045

0.0045

0.0023

0.0045

0.0068

0.009

0.009

0.009

0.009

0.00856

Sample 7

0.25

0.343

0.222

0.353

0.255

0.2846

(Joules)
Sample 9 Sample 10 AVE

$\begin{array}{lll}0.0067 & 0.0068 & 0.00515\end{array}$

$\begin{array}{lll}0.0067 & 0.009 & 0.00783\end{array}$

$\begin{array}{lll}0.0067 & 0.009 & 0.00893\end{array}$

$\begin{array}{lll}0.0067 & 0.009 & 0.00627\end{array}$

$\begin{array}{lll}0.0067 & 0.0046 & 0.00583\end{array}$

$0.0067 \quad 0.00768$

Sample 8 Sample 9 Sample 10 AVE

$\begin{array}{llll}0.245 & 1.2 & 0.316 & 0.5016\end{array}$

$\begin{array}{llll}0.3 & 0.261 & 0.218 & 0.264\end{array}$

$\begin{array}{llll}0.414 & 0.48 & 0.245 & 0.3284\end{array}$

$\begin{array}{llll}0.462 & 0.364 & 0.3 & 0.3452\end{array}$

$\begin{array}{llll}0.194 & 0.222 & 0.194 & 0.3246\end{array}$

$\begin{array}{lll}0.323 & 0.5054 & 0.2546\end{array}$

Scaling

factor for

sensor

0.007013 


\begin{tabular}{|c|c|c|c|c|c|c|c|c|c|c|c|}
\hline $\mathrm{Cm}$ & Sample 1 & Sample 2 & Sample 3 & Sample 4 & Sample 5 & Sample 6 & Sample 7 & Sample 8 & Sample 9 & Sample 10 & AVE \\
\hline 1 & $3.15585 \mathrm{E}-05$ & $1.61 \mathrm{E}-05$ & $3.09 \mathrm{E}-05$ & $3.09 \mathrm{E}-05$ & $3.09 \mathrm{E}-05$ & 4.7E-05 & $3.16 \mathrm{E}-05$ & 4.77E-05 & 4.7E-05 & $4.77 \mathrm{E}-05$ & $3.61 \mathrm{E}-05$ \\
\hline 2 & $3.15585 \mathrm{E}-05$ & $3.23 \mathrm{E}-05$ & $7.85 \mathrm{E}-05$ & $6.17 \mathrm{E}-05$ & $3.09 \mathrm{E}-05$ & $9.4 \mathrm{E}-05$ & 4.7E-05 & $6.31 \mathrm{E}-05$ & 4.7E-05 & $6.31 \mathrm{E}-05$ & $5.49 \mathrm{E}-05$ \\
\hline 3 & 4.69871E-05 & $6.31 \mathrm{E}-05$ & $7.78 \mathrm{E}-05$ & $6.17 \mathrm{E}-05$ & 7.78E-05 & $9.4 \mathrm{E}-05$ & $3.16 \mathrm{E}-05$ & $6.31 \mathrm{E}-05$ & 4.7E-05 & $6.31 \mathrm{E}-05$ & $6.26 \mathrm{E}-05$ \\
\hline 4 & $3.15585 \mathrm{E}-05$ & $3.23 \mathrm{E}-05$ & $7.78 \mathrm{E}-05$ & $3.09 \mathrm{E}-05$ & $3.09 \mathrm{E}-05$ & $3.16 \mathrm{E}-05$ & $3.16 \mathrm{E}-05$ & $6.31 \mathrm{E}-05$ & 4.7E-05 & $6.31 \mathrm{E}-05$ & $4.4 \mathrm{E}-05$ \\
\hline 5 & $3.15585 \mathrm{E}-05$ & $3.23 \mathrm{E}-05$ & $7.78 \mathrm{E}-05$ & $4.63 \mathrm{E}-05$ & $3.09 \mathrm{E}-05$ & $3.16 \mathrm{E}-05$ & $1.61 \mathrm{E}-05$ & $6.31 \mathrm{E}-05$ & 4.7E-05 & $3.23 \mathrm{E}-05$ & 4.09E-05 \\
\hline Isp & Sample 1 & Sample 2 & Sample 3 & Sample 4 & Sample 5 & Sample 6 & Sample 7 & Sample 8 & Sample 9 & Sample 10 & AVE \\
\hline 1 & 0.067991845 & 0.076453 & 0.064424 & 0.032212 & 0.032212 & 0.033028 & 0.025484 & 0.024975 & 0.122324 & 0.032212 & 0.051131 \\
\hline 2 & 0.03058104 & 0.029867 & 0.02314 & 0.022222 & 0.024465 & 0.024465 & 0.034964 & 0.030581 & 0.026606 & 0.022222 & 0.026911 \\
\hline 3 & 0.0254842 & 0.043731 & 0.018043 & 0.029867 & 0.03945 & 0.03945 & 0.02263 & 0.042202 & 0.04893 & 0.024975 & 0.033476 \\
\hline 4 & 0.032212029 & 0.040775 & 0.018858 & 0.033028 & 0.047095 & 0.029154 & 0.035984 & 0.047095 & 0.037105 & 0.030581 & 0.035189 \\
\hline 5 & 0.043730887 & 0.053211 & 0.020082 & 0.04893 & 0.045362 & 0.031397 & 0.025994 & 0.019776 & 0.02263 & 0.019776 & 0.033089 \\
\hline
\end{tabular}




\section{Appendix E. Load Cell Calibration}

\subsection{Gram Pendulum Dropped From 4565 and 90 Degrees}

Table 8. Load Cell vs. Analytical Results at 45, 65, 90 Degrees for a 0.1 Gram Pendulum

\begin{tabular}{|l|l|l|}
\hline Angle & Sensor & Analytical \\
\hline 45 & 0.29271 & 0.0075 \\
\hline 65 & 1.1183 & 0.010638 \\
\hline 90 & 2.2479 & 0.014 \\
\hline
\end{tabular}

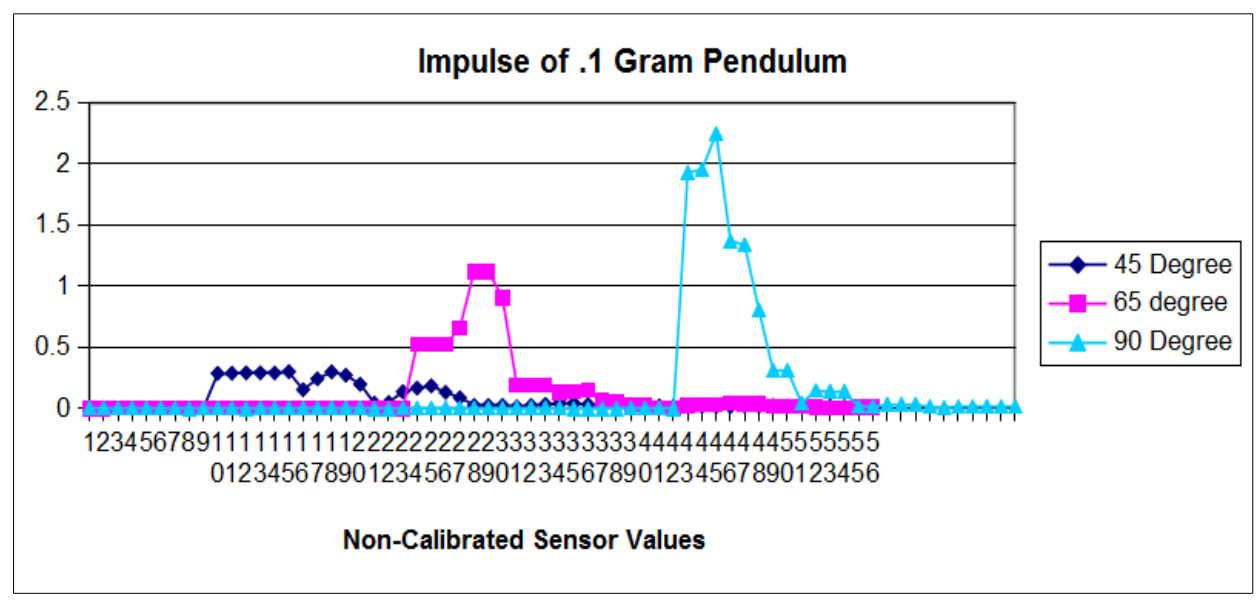

Figure 22. Load Cell Calibration plots of 0.1 Gram Pendulum at 4565 and 90 degrees

\subsection{Gram Pendulum Dropped From 4565 and 90 Degrees}

Table 9. Load Cell vs. Analytical Results at 45, 65, 90 Degrees for a 0.2 Gram Pendulum

\begin{tabular}{|l|l|l|}
\hline Angle & Sensor & Analytical \\
\hline 45 & 1.776 & 0.03423 \\
\hline 65 & 2.57687 & 0.04806 \\
\hline 90 & 3.64789 & 0.06325 \\
\hline
\end{tabular}




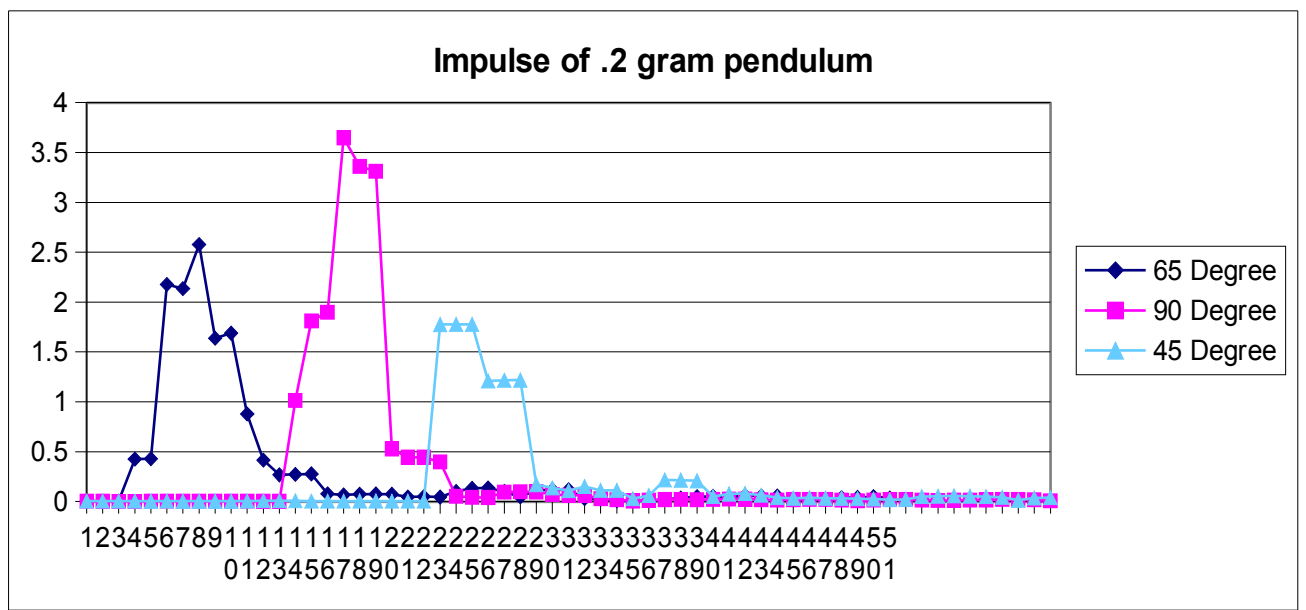

Figure 23. Load Cell Calibration plots of 0.2 Gram Pendulum at 6590 and 45 Degrees 